\title{
Evaluation of Polymers for Fast Neutron Personnel Dosimetry by the Electrochemical Etching Technique
}

\author{
S. A. Johnson \\ P. L. Ziemer \\ R. B. Gammage \\ J. H. Thorngate
}




\section{DISCLAIMER}

This report was prepared as an account of work sponsored by an agency of the United States Government. Neither the United States Government nor any agency Thereof, nor any of their employees, makes any warranty, express or implied, or assumes any legal liability or responsibility for the accuracy, completeness, or usefulness of any information, apparatus, product, or process disclosed, or represents that its use would not infringe privately owned rights. Reference herein to any specific commercial product, process, or service by trade name, trademark, manufacturer, or otherwise does not necessarily constitute or imply its endorsement, recommendation, or favoring by the United States Government or any agency thereof. The views and opinions of authors expressed herein do not necessarily state or reflect those of the United States Government or any agency thereof. 


\section{DISCLAIMER}

Portions of this document may be illegible in electronic image products. Images are produced from the best available original document. 


\section{Printed in the United States of America. Available from National Technical Information Service \\ U.S. Department of Commerce 5285 Port Royal Road, Springfield, Virginia 22161 \\ Price: Printed Copy $\$ 5.25$; Microfiche $\$ 3.00$}

This report was prepared as an account of work sponsored by an agency of the United States Government. Neither the United States Government nor any agency thereof, nor any of their employees, contractors, subcontractors, or their employees, makes any warranty, express or implied, nor assumes any legal liability or responsibility for any third party's use or the results of such use of any information, apparatus, product or process disclosed in this report, nor represents that its use by such third party would not.infringe privately owned rights. 
ORNL/TM-6167

Dist. Category UC-41

Contract No. W-7405-eng-26

HEALTH AND SAFETY RESEARCH DIVISION

\section{EVALUATION OF POLYMERS FOR FAST NEUTRON PERSONNEL DOSIMETRY BY THE ELECTROCHEMICAL ETCHING TECHNIQUE}
S. A. Johnson
P. L. Ziemer ${ }^{1}$
R. B. Gammage
J. H. Thorngate

\section{IBionucleonics Department \\ Purdue University}

Submitted by S. A. Johnson as a thesis to the Graduate School of the Purdue University in partial fulfillment of the requirements for the degree of Master of Science

Dạte Published: December 1978

OAK RIDGE NATIONAL LABORATORY

Oak Ridge, Tennessee 37830 operated by

UNION CARBIDE CORPORATION for the

DEPARTMENT OF ENERGY

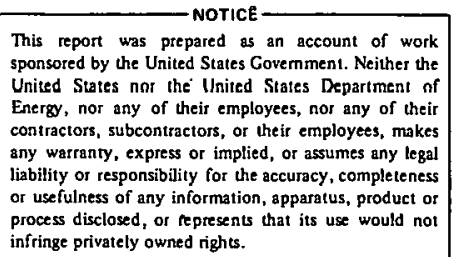

res. 
THIS PAGE

\section{WAS INTENTIONALLY}

: LEFT BLANK 
ACKNOWLEDGMENTS

Sincere appreciation is extended to the staff of the Bionucleonics Department at Purdue University for their generosity and moral support throughout this research.

Thanks are extended to Mr. Dan Christian and Mr. Clyde Littleton of the DOSAR facility at ORNL for their ideas and electronics expertise.

Appreciation is extended to Mr. Howard Dickson, Mr. Don Ward, and Mr. Walt Gilley for their assistance during experimentation.

One of us (SAJ) wishes now to express her deep appreciation to her husband, Jerry, for his encouragement and patience throughout this research. Sincere gratitude also goes to her mother for encouraging her graduate studies.

Appreciation is extended to the U.S. Department of Energy for their support of S. A. Johnson through the Radiation Protection Traineeship Program under Contract Number AT-(40-1)-3497. 


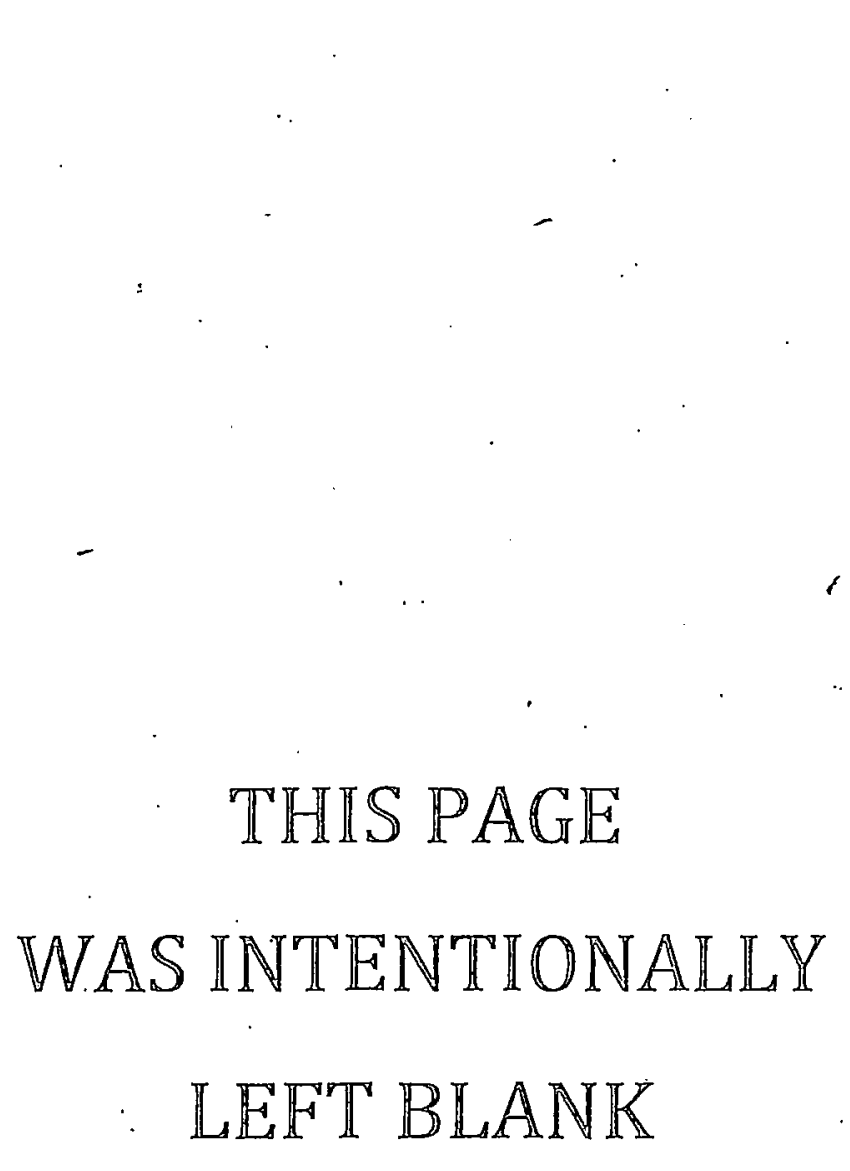


CONTENTS

LIST OF TABLES . . . . . . . . . . . . . . . . . . . vi

LIST OF FIGURES. . . . . . . . . . . . . . . . . . . vii

ABSTRACT . . . . . . . . . . . . . . . . . . $\mathrm{ix}$

INTRODUCTION . . . . . . . . . . . . . . . . . . . 1

LITERATURE REVIEW. . . . . . . . . . . . . . . . 3

Development of Personnel Neutron Dosimeters . . . . . . 3

Track Registration Techniques .. . . . . . . . . . . 5

MATERIALS AND METHODS. . . . . . . . . . . . . . . . 11

Experimental Design ................... . . 11

Electrochemical Etching Instrumentation and Procedures. . 12

Recoil Particle Track Counting Technique. . . . . . . . 15

Irradiation Facilities and Experimental Systems . . . . . 15

Leakage Current Measurement Instrumentation. . . . . 16

Shielding Experimentation. . . . . . . . . . 16

RESULTS AND DISCUSSION . . . . . . . . . . . . . . . 19

Effect of Polymer Type on Track Appearance . . . . . . 19

Cellulose Acetate. ............... 20

Cellulose Triacetate ............ . 24

Cellulose Acetobutyrate. . . . . . . . . . 27

Polycarbonate. . . . . . . . . . . . . 30

Effect of Storage Temperature on Lexan. . . . . . . . 36

Effect on Background Track Density : . . . . . . . 36

Effect on Recoil Particle Track Derlsity . . . . . . 38

Differential Leakage Current Measurement. . . . . . . . . . 40

Response to Different Neutron Spectra... . . . . . 40

SUMMARY AND RECOMMENDATIONS . . . . . . . . . . . . . . . 44

Summary ........................ 44

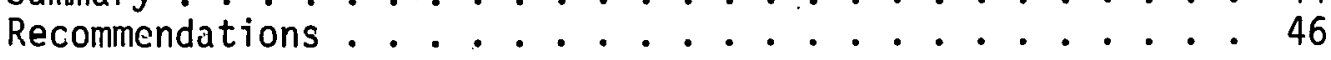

REFERENCES ....................... 49 
LIST OF TABLES

Table

1 Properties of Commercial Plastics .......... 20

2 Response of Polycarbonates to Different Neutron Spectra from HPRR ..................... 42 
vi $i$

\section{LIST OF FIGURES}

\section{Figure}

1 Electrochemical Etching Apparatus . . . . . . . 13

2 Schematic Diagram of Current Amplifier. . . . . . . 17

3 Calculated Neutron Spectra at Three Meters for the HPRR. .................... 18

4 Optical Micrograph of Fast Neutron-Induced Recoil

Particle Tracks in $762 \mu \mathrm{m}$ Thick Cellulose Acetate, Electrochemically Etched for Four Hours in $30 \% \mathrm{KOH}$ at $1000 \mathrm{~V}$ and $1000 \mathrm{~Hz}(500 \mathrm{X}) . . . . .21$

$5 \quad$ Scanning Electron Micrograph of Recoil Particle Tracks in $762 \mu \mathrm{m}$ Thick Cellulose Acetate, Etched for Four Hours in $30 \% \mathrm{KOH}$ at $1000 \mathrm{~V}$ and $1000 \mathrm{~Hz}(1000 \mathrm{X}) . . . . .22$

6 Optical Micrograph of Recoil Particle Tracks in $762 \mu \mathrm{m}$ Thick Cellulose Acetate, Etched for Eight Hours in $30 \%$ $\mathrm{KOH}$ at $1000 \mathrm{~V}$ and $1000 \mathrm{~Hz}(500 \mathrm{X}) . . . . . .2 . .23$

7 Optical Micrograph of Recoil Particle Tracks in $250 \mu \mathrm{m}$ Thick Cellulose Triacetate, Etched for Four Hours in $30 \%$ $\mathrm{KOH}$ at $500 \mathrm{~V}$ and $500 \mathrm{~Hz}(500 \mathrm{X}) . . . . . . . .25$

8 Scanning Electron Micrographs of Recoil Particle Tracks in $250 \mu \mathrm{m}$ Thick Cellulose Triacetate, Etched for Four Hours in $30 \% \mathrm{KOH}$ at $500 \mathrm{~V}$ and $500 \mathrm{~Hz}$, magnified at (a) $300 \mathrm{x}$, and (b) $1000 \mathrm{x}$............... 26

$9 \quad$ Optical Micrograph of Recoil Particle Tracks in $250 \mu \mathrm{m}$ Thick Cellulose Acetobutyrate, Etched for Four Hours in $30 \% \mathrm{KOH}$ at $500 \mathrm{~V}$ and $500 \mathrm{~Hz}(500 \mathrm{X})$. . . . . . . 28

10 Scanning Electron Micrograph of a Recoil Particle Track in $250 \mu \mathrm{m}$ Thick Cellulose Acetobutyrate, Etched for Four Hours in $30 \% \mathrm{KOH}$ at $500 \mathrm{~V}$ and $500 \mathrm{~Hz}(1000 \mathrm{X})$. . . . . 29

11 Photograph of Recoil Particle Tracks in $250 \mu \mathrm{m}$ Thick Lexan Exposed to Different Doses of Fission Neutrons from the HPRR, Etched for Four Hours in $30 \% \mathrm{KOH}$ at $1000 \mathrm{~V}$ and $1000 \mathrm{~Hz}$................. 31 
12 Optical Micrograph of a Recoil Particle Track in $250 \mu \mathrm{m}$ Thick Lexan Etched for Four Hours in 30\%

$\mathrm{KOH}$ at $1000 \mathrm{~V}$ and $1000 \mathrm{~Hz}(500 \mathrm{X}) \ldots 32$

13 Optical Micrograph of Recoil Particle Track Size Distribution in $250 \mu \mathrm{m}$ Thick Lexan Etched for Four Hours in $30 \% \mathrm{KOH}$ at $1000 \mathrm{~V}$ and $1000 \mathrm{~Hz}(100 \mathrm{X}) . . . .33$

14 Scanning Electron Micrograph of a Recoil Particle Track in $250 \mu \mathrm{m}$ Thick Transilwrap Etched for Four Hours in $30 \% . \mathrm{KOH}$ at $1000 \mathrm{~V}$ and $1000 \mathrm{~Hz}(300 \mathrm{X}) . \ldots 34$

15 Scanning Electron Micrograph of a Recoil Particle Track in $250 \mu \mathrm{m}$ Thick Lexan Etched for Four Hours in $30 \% \mathrm{KOH}$ at $1000 \mathrm{~V}$ and $1000 \mathrm{~Hz}(1000 \mathrm{X}) . \ldots . \ldots . . . . . .35$

16 Background Track Density as a Function of Time at Indicated Temperatures .......... . 37

17 Recoil Particle Track Density as a Function of Time at Indicated Temperatures. . . . . . . . . 39

18 Differential Leakage Current in Terms of Voltage . . . 41 


\section{ABSTRACT}

Johnson, Sherri Alice. M.S., Purdue University, August 1977. Evaluation of polymers for fast neutron dosimetry by the electrochemical etching technique. Major Professor: Paul L. Ziemer.

Four plastics have been evaluated as potential fast neutron dosimeters, namely cellulose acetate, cellulose triacetate, cellulose acetobutyrate and polycarbonate. The technique of nuclear track registration in the plastics was used as the method of dosimetry.

Irradiated polymer foils were etched under standard etching conditions of four hours at $25^{\circ} \mathrm{C}$ in a solution of $30 \% \mathrm{KOH}$ (by weight) using electrodes operated at 1000 volts (RMS) and $1000 \mathrm{~Hz}$. Development of a spongy texture in the cellulose acetate and clouding of the cellulose triacetate surface rendered the two unsuitable. High water absorptivity $(2-7 \%)$ was responsible for loss of track identity in the two polymers. Lowering the voltage and frequency ( 500 volts, $500 \mathrm{~Hz}$ ) improved contrast in the cellulose triacetate between the tracks and the background (less clouding). The acetobutyrate, having the lowest dielectric and tensile strengths of the four, developed fully penetrated cracks which caused shorting of the electrochemical cells containing $\mathrm{KOH}$. Clouding by absorption of water was not serious enough to interfere with track visibility. Polycarbonate had the highest dielectric and tensile strength, volume resistivity, and the lowest water absorptivity of the four plastics. It. also yielded the most highly contrasted electrochemically etched tracks and did not experience stress cracking. It was clearly the best of the four polymers for the general purpose of fast neutron personnel dosimetry. 
In each of the four plastics, the electrochemically etched tracks had roughiy the same form of a subsurface cavity with a small entrance hole at a partially collapsed surface. Scanning electron micrographs revealed the surface structure, while optical micrographs showed the larger, subsurface cavities that were visually observed. At the voltage and frequency used for these etchings (1000 volts, $1000 \mathrm{~Hz}$ ), track shape and contrast for counting purposes were superior in the Lexan* polycarbonạte

Background track density in unirradiated polycarbonate became a problem in the Lexan. Attempts to reduce the track density, so as to measure low doses (a few tens of mrad) of fast neutrons, were not successful. Either there was no change in background track density $\left(100^{\circ} \mathrm{C}\right)$ or else the undesired result of an increase in track density was obtained $\left(120^{\circ} \mathrm{C}\right.$ and $\left.140^{\circ} \mathrm{C}\right)$.

Two polycarbonates (Lexan and Transilwrap ${ }^{\dagger}$ ), of thickness $250 \mu \mathrm{m}$, were examined as neutron dosimeters in the three standard neutron fields of the Health Physics Research Reactor (HPRR) at doses of 50 or 100 mrad. The background track densities in the Lexan and Transilwrap were $78 \pm 14$ and $11 \pm 2$ tracks $/ \mathrm{cm}^{2}$, respectively. The response of the Lexan polycarbonate to exposures from the three neutron spectra obtained from the unshielded HPRR reactor, the HPRR with a 12-cm-thick Lucite shield and the HPRR with 13-cm-thick steel shield were $\sim 0.08, \sim 0.04, \sim 0.02 \mathrm{track} / \mathrm{cm}^{2}-\mathrm{mrem}$, respectively. The Transilwrap responses were $\sim 0.04, \sim 0.02$, and $\sim 0.03$ tracks/ $\mathrm{cm}^{2}$-mrem for the unshielded, Lucite-shielded, and steel-shielded conditions, respectively. The response ratios of unshielded-to-Lucite and Lucite-to-steel 太Lexan is registered trademark of General Electric Co., Pittsfield, Mass. Transilwrap is registered trademark of Tuffak, Inc., Kensington, Conn. 
for the Lexan and Transilwrap, when evaluated on the basis of the known neutron spectra of the HPRR, seem to imply that the Transilwrap responds more efficiently to lower energy neutrons than the Lexan. Due to the large errors encountered when measuring these small doses, further experimentation is needed for this type of evaluation. 


\section{INTRODUCTION}

Efficient fast neutron personnel dosimetry is a problem of concern in many areas of health physics and radiotherapy. The need is apparent for dosimetric techniques for both routine and accidental exposure evaluation. The present state-of-the-art fast neutron personnel dosimeters leave room for improvement.

Special nuclear track emulsions with their many drawbacks (fogging by other types of radiation, post-irradiation fading, limited dose range, etc.) have been replaced in many laboratories by the thermoluminescence albedo-neutron dosimeters. They, too, have disadvantages, particularly serious energy dependence.

Among the various existing methods having the potential of being improved, track etching methods are among the most promising. Track etching is based on charged particles being registered in a sensitive insulator, such as an organic polymer, resulting in a narrow track of "damage" along the particle's path. These damage tracks can be made visible by a chemical etching technique, enhancing them more readily than the surrounding undamaged areas until they are large enough to be seen microscopically (Fleischer, Price, and Walker, 1975).

In this research, an electrochemical etching method, originally proposed by Tommasino and Armellini (1970), was studied for the enhancement of fast neutron-induced recoil particle tracks in several organic polymers. This method appears to be a superior way of amplifying tracks in polymers, particularly polycarbonate. 
The electrochemical etching technique has been examined extensively by Mehdi Sohrabi who has optimized many of its parameters (Sohrabi, 1974 and 1975; Sohrabi and Morgan, 1976). He has stated that polycarbonate is the most suitable of the organic polymers for track enhancement by this method without elaboration of evidence to support his conclusion (Sohrabi, 1974). Several hypotheses have been made regarding the mechanism involved in the amplification of tracks when electrochemically etched, none of which are in exact agreement with each other (Tommasino and Armellini, Iy/U; Sóhrab1 and Murgan, Februdry 1970).

In this research Lexan polycarbonate as well as three cellulose derivatives were examined and evaluated as to their suitability for electrochemically etching fast neutron-induced recoil particle tracks. Examination of these etch pits was performed using both optical and scanning electron microscopy.

The effects of storage temperature on background and recoil particle track densities in Lexan were studied to evaluate this polycarbonate regarding its stability and reproducibility as a personnel dosimeter.

An investigation was also conducted, in this study, to determine a frequency where leakage current differences between damaged (irradiated) and undamaged foils is maximized. This value would represent the optimum frequency for enhancement of electrochemically etched rccoil tracks. Response of polycarbonate to different neutron spectra has not been well documented. In this study, three neutron spectra were chosen to examine the response (tracks $/ \mathrm{cm}^{2}-\mathrm{mrem}$ ) of two polycarbonates, Lexan and Transilwrap. 


\section{LITERATURE REVIEW}

\section{Development of Personnel Neutron Dosimeters}

Integrating dosimeters for the ionizing radiations of alpha, beta, and gamma rays are satisfactorily developed with the possible exception of the low energy beta emitters (i.e., ${ }^{3} \mathrm{H}$ and ${ }^{14} \mathrm{C}$ ). Fast neutron dosimetry remains as an unresolved problem. $\dot{A}$ good neutron personnel dosimeter should:

1) be sensitive to neutrons over a wide dose range in order to be used for both routine and accidental dosimetry limits $(0.001$ to 1000 rads), yet insensitive to other radiations (i.e., alpha, beta and gamma rays) or at least present a way to compensate for the response from these other radiation forms;

2) be independent of the direction of incidence of the neutron beam when it impinges on the dosimeter since the dose may result from a beam of unknown direction;

3) be stable with regards to image fading (e.g., charged particle tracks);

4) possess an energy response similar to the kerma or rem curves for tissue as recommended by authorities such as ICRP; and

5) be rugged, inexpensive, readily available, and easily analyzed.

Proton track registration in special nuclear track emulsions was, until recently, the only widespread neutron personnel dosimetry method. It is based on the elastic scattering of fast neutrons with hydrogen 
atoms in the emulsion, producing proton recoils which register in the film as tracks. The thermal neutron component is measured from proton recoil tracks which register in the film resulting from the $1.4 \mathrm{~N}$ $(n, p){ }^{14} \mathrm{C}$ reaction. Discriminating between the two sets of proton tracks is done by shielding some portion of the film with cadmium. This technique measures neutron flux rather than absorbed dose and has other serious drawbacks, particularly fogging by other types of radiation, and serious fading of tracks, particularly at higher temperatures and humiditics (Becker, 1973).

Due to these obvious disadvantages, many attempts have been made to develop another method for neutron personnel dosimetry. Alternatives include:

1) thermoluminescent albedo dosimeters;

2) fission fragment track registration dosimeters; and

3) fast neutron-induced recoil particle track registration dosimeters.

Albedo-neutron dosimeters are based on detectiun of thermalized neutrons arising from scattered fast neutrons reflected by the bodies of personnel. These dosimeters usually incorporate one or two pairs of 6LiF and ${ }^{6}$ LiF thermoluminescent dosimeters (TLD) in a cover of cadmium to respond only to thermal neutrons backscattered from the body. The thermoluminescence phosphors are gamma sensitive but the ${ }^{7}$ LiF TLD compensates for any gamma dose received. Hankins (1973) has done extensive research on these particular dosimeters and has determined that their sensitivity decreases rapidly as fast neutron energy increases, particularly above $0.1 \mathrm{MeV}$. His research also indicates that a major problem lies with the leakage of thermal neutrons. Thermal-neutron leakage around the dosimeter cannot be eliminated using reasonable-size 
dosimeters. Moving the dosimeter away from the body or wearing it backwards can also cause large errors in dosimeter response. Although attempts have been made to improve these obvious drawbacks, the albedoneutron dosimeter is usually complex in design, and because of its severe energy dependence it is acceptable only in areas where the neutron energy spectrum is known.

The phosphors used in these dosimeters have a characteristic which can be considered either as an advantage or disadvantage depending on the point of view: they can be used repeatedly. While this results in a reduction in expense, the dosimeter cannot serve as a permanent record of dose received by the individual.

\section{Track Registration Techniques}

Fleischer, Price and Walker (1975) began studying track registration by preferential etching in insulators in 1962, as described by Young (1958). These three men showed in their extensive research that tracks could be made visible by chemical agents (etchants) in several dielectrics (e. g., mica, glasses, and particularly organic polymers). "Damaged" regions, or tracks, are produced in these materials by heavy, charged particles. These "damage" tracks are highly susceptible to chemical attack. Besides heavy, densely-ionizing particles, alpha particles up to several MeV and even protons of $\sim 100 \mathrm{keV}$ have been detected in the most sensitive organic polymer, cellulose nitrate, by this chemical etching method (Johnson and Becker, 1970). These dielectric materials are readily available and inexpensive but the tracks are small and require tedious microscopic counting. 
Chemical track etching has expanded into several areas of radiation dosimetry, particularly neutron dosimetry. One technique utilizes fissionable materials, such as milligram quantities of ${ }^{237} \mathrm{~Np},{ }^{235} \mathrm{U}$, or ${ }^{232} \mathrm{Th}$ in conjunction with a polymer foil in which fission fragment tracks are registered (Fleischer, Price and Walker, 1975). Conventional chemical etching (immersing the irradiated foil into an etchant such as sodium hydroxide or potassium hydroxide) has been used to etch the "damage" tracks in the foils, large enough to be seen microscopically. Even though this technique is very sensitive for neutron energies greater than $\sim 0.4 \mathrm{MeV}$, it can present a hazard due to the use of fissionable materials. Furthermore, the cost of using fissionable materials is higher than desired.

To avoid this health hazard, another approach has been made to evaluate personnel exposure to neutrons. Elastically scattered recoil particles (carbon and oxygen in the organic polymers) and alpha tracks (from $(n, \alpha)$ reactions induced by fast neutrons) have been recorded in organic insulators such as cellulose derivatives and polycarbonate (Sohrabi and Morgan, 1976). The tracks, however, are very small and have poor contrast against the undamaged regions of the foils. There are no fissionable materials involved; therefore, the cost is very low and the health hazard non-existent.

Spark counting has been used to improve etching and detection in fission-fragment track registration (Cross and Tommasino, 1970). It has also been found applicable in recoil particle track registration using extended conventional etching methods in thin foils of polycarbonate and cellulose nitrate (Becker and Razek, 1975; Jasaik and Piesch, 1975). 
Foils thin enough for sparking $(6 \mu \mathrm{m}-12 \mu \mathrm{m})$ have a high breakage risk during the etching process. Accidental or unnecessary movement of the foils over the electrode or successive sparking increases the count density thus giving inaccurate data. Etching times for spark counting are longer than for conventional etching methods without sparking. Tommasino and Armellini (1970) proposed an electrochemical etching method to enhance track visibility of recoil particle tracks in polymers. In polycarbonate, recoil tracks have been amplified in diameter so as to be made visible to the unaided eye. In conventional chemical etching, the damage tracks are more susceptible to chemical attack than the undamaged areas of the polymer. Their hypothesis is that the passage of the etchant through these damaged areas produces conductive paths in the foil, and if an alternating current is passed through the dielectric material, currents can be produced in these conductive regions. He states further that "the conduction currents due to the absorbed ions, and other dielectric losses, generate heat continuously in the electrically stressed dielectric materials" (Tommasino and Armellini, 1970). Sohrabi and Morgan (February 1976), who have performed extensive research on electrochemical etching, hypothesize that track enhancement is due to the increased movement of the $\mathrm{OH}$ ions through the damaged areas, essentially replenishing the $\mathrm{OH}$ ions in the tracks, and thus increasing the etch rate. The actual mechanism for track amplification for the electrochemical etching technique is yet to be determined.

An interesting characteristic of this etching method was observed by Griffith (1976). Upon viewing electrochemically etched recoil tracks in polycarbonate with a scanning electron microscope, he discovered that 
most of the tracks were below the surface with only a narrow $(20.5 \mu \mathrm{m})$ track connecting to the surface. The etch pits appeared as slight depressions in the sample surface which collapsed when the magnification was increased. He offered no explanation for this phenomenon.

Electrochemical etching depends on several parameters which have been optimized by Sohrabi and Morgan (1976). These include dielectric material, voltage and frequency, thickness of the dielectric, operating temperature, type and concentration of etchant.

Sohrabi (1974) reported a polycarbonate dielectric material produced the best results when electrochemically etched. He did not elaborate as to how it compared to the cellulose derivatives, the polymers used most extensively for conventional etching techniques. Based on his conclusion regarding polycarbonate, he optimized electrochemical etching parameters for the material. Voltages of 600 to 1000 volts and frequencies of $\sim 2000 \mathrm{~Hz}$ resulted in optimum mean track diameter, sensitivity (tracks/ $\mathrm{cm}^{2}-$ rad), and optical density measurements (Sohrabi, 1975).

Application of electrochemical etching is strongly dependent on foil thickness. The thinner polycarbonate foils $(100 \mu \mathrm{m}-300 \mu \mathrm{m})$ are more sensitive and extend the applicable neutron dose range to iưu rads, but thicker foils exhibit larger tracks (Sohrabi and Morgan, February 1976).

As etchant temperature increases, required etching time for comparable results decreases. Track density and mean track diameter as functions of temperature are linear up to $60^{\circ} \mathrm{C}$ (the maximum value used in Sohrabi's research). Potassium hydroxide (KOH) appears to be a 
better etchant than sodium hydroxide $(\mathrm{NaOH})$ for obtaining larger tracks and higher track densities in shorter etching times. Track density increases as etchant concentration increases, but mean track diameter measurements peak at concentrations of $\sim 30 \%$ and $\sim 45 \%$ (\% by weight) for $\mathrm{KOH}$ etchants.

Sohrabi (1974) has illustrated how easily and quickly numbers of foils can be sorted according to neutron doses they receive. Track density differences in polycarbonate foils receiving doses of $7 \mathrm{mrad}$, $70 \mathrm{mrad}, 700 \mathrm{mrad}, 11 \mathrm{rad}, 99 \mathrm{rad}$, and $1020 \mathrm{rad}$ are very pronounced. A good estimate of the neutron dose can be made by viewing the foil and comparing visually a set of standard irradiated and electrochemically etched foils. Sohrabi has noted that for doses up to 10 rads, track density could be obtained by projecting the foil on a microfiche screen. Track density as a function of dose by track counting is linear up to 10 rads. For doses greater than 10 rads, optical density changes are significant and are linear from 10 to 1000 rads.

Directional dependence of direct interaction of the foil with neutrons is more pronounced than when the fissionable materialspolycarbonate system is irradiated, but even this system displays some directional dependence. Sohrabi has offered some solutions to compensate for this problem:

1) if direction is known (i.e. therapy), corrections can be made for the angle;

2) bend foils in circular or semi-circular shape around a Lucite tube which would result in a straight 1 ine by counting tracks in the foil strip facing the direction of the beam; or 
3) mounting two or more foils on walls of a small tube for area monitoring.

The response function of recoil particle track registration follows approximately the shape of the curve of "dose equivalent" per unit neutron fluence as a function of neutron energy as defined by ICRP. Spectral distribution, according to Sohrabi, can be determined from track size distribution. The track size is dependent on type and energy of the incident neutron, the angle of incidence and etching conditions. The average range of a fast neutron-induced recoil nucleus increases with an increase in the energy of the colliding neutron. Average depth and diameter, therefore, could be used as a measure of neutron energy.

A problem of concern with any neutron dosimetry system is the gamma radiation almost always accompanying a neutron beam. It has been found, however, that the recoil particle track registration method shows sensitivity to gamma rays only if the gamma dose is high enough "to simulate the threshold dose $\left(27.5 \times 10^{6}\right.$ rads in Lexan polycarbonate) delivered to a polymer by a charged particle around its trajectory" (Katz and Kobetich, 1968). In practical applications, the gamma energy and dose are usually very low compared to this.

Despite the obvious advantages of electrochemically etching fast neutron-induced recoil particle tracks, there exists a major disadvantage regarding its use as a personnel dosimeter. The threshold neutron energy for recoil particle track registration is $\sim 7 \mathrm{MeV}$, below which carbon and oxygen recoil tracks due to elastic scattering of neutrons do not register in polycarbonate. (Jozefowicz, 1971) Recommendations to possibly remedy this problem of threshold energy are discussed in the Summary. 
MATERIALS AND METHODS

\section{Experimental Design}

To meet the objectives of this research, four polymers were selected for evaluation, namely cellulose acetate, cellulose triacetate, cellulose acetobutyrate and polycarbonate. Sohrabi (1974) studied these polymers and concluded that polycarbonate is the most suitable for track enhancement using the electrochemical etching technique without elaborating as to how it compared to the others tested.

In order to intercompare the four polymers, standard etching conditions were chosen as follows:

1) $1000 \mathrm{volts}$
2) $1000 \mathrm{~Hz}$
3) $30 \% \mathrm{KOH}$
4) four hours.

As a result of electrochemical etching parameter optimization by Sohrabi (1975), the above conditions were selected. He found voltages of 600 to $1000 \mathrm{~V}$ and frequencies of 1000 to $2000 \mathrm{~Hz}$ produced optimum mean track diameter, sensitivity (tracks/ $\mathrm{cm}^{2}-\mathrm{rad}$ ), and optical density measurements. Etchant concentrations of $\sim 30 \% \mathrm{KOH}$ and $245 \% \mathrm{KOH}(\%$ by weight) yielded maximum mean track diameter measurements. Sensitivity increased as a function of etching time but began to level off after four hours in the thinner polycarbonates $(125 \mu \mathrm{m}$ and $250 \mu \mathrm{m})$.

A standard neutron test dose of one rad was used because it was assumed to yield a sufficient recoil particle track density for track appearance evaluation in the polymers. 
Depending on the result of the responses of the polymers under these standard conditions, the experimental design included an evaluation of the response of the most promising polymer as a function of dose, and a determination of an optimum frequency for track enhancement. The effects of storage temperature on background and recoil particle track densities in Lexan were also investigated.

The major portion of the instrumentation for track amplification was an electrochemical etching system designed and constructed at the DOSAR facility at the Oak Ridge National Laboratory. The system consisted of an electrochemical etching chamber and a high voltage supply in conjunction with an audio-oscillator to maintain the voltages and frequencies of interest, respectively (Thorngate, Christian, and Littleton, 1976). This system and methods for foil irradiations are discussed in the following sections.

\section{Electrochemical Etching Instrumentation and Procedures}

An electrochemical etching system for large scale etching requires a special chamber capable of holding several foils simultaneously. The etching chamber used in this research was designed to hold six plastic foils. It consisted of two cylindrical lucite containers, each of which were $12 \mathrm{~cm}$ long and $10 \mathrm{~cm}$ in diameter (Figure 1). A slit was made at the top of each container for the entrance of an electrode into the etching solution.

Each $81 / 2$ inch by 11 inch polymer sheet was covered on both sides by tissue paper to prevent scatching before 2-cm-diameter foils were punched out on a Di-Arco Corporation Punch, number 1-1214. 


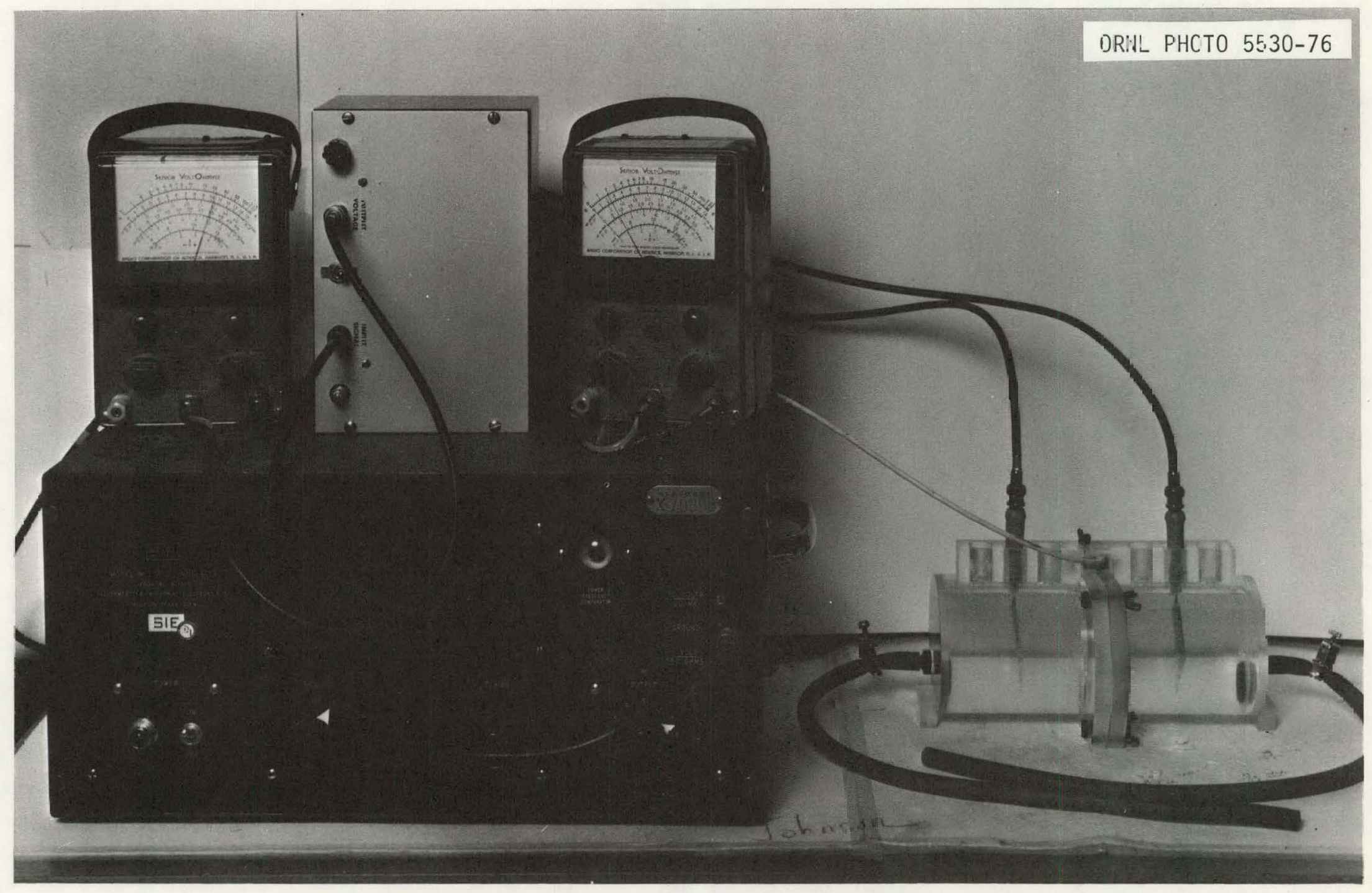

Fig. 1. Electrochemical Etching Apparatus. 
The foils to be etched were placed in windows between the containers with each foil held firmly in place by two rubber "0" rings on either side of the foil. The containers were held together by means of four screws and wingnuts. Careful handling of the foils is necessary to prevent any puncture as this will result in leakage of the etchant between the two containers and subsequently halt the etching process.

The enhancement of recoil particle tracks by electrochemical etching requires a high voltage power supply having variable output voltages incorporated with an audio-oscillator for frequency variations of square or sinusoidal waveforms. The power supply used in this research was constructed at the DOSAR. The oscillator was a Southern Industrial Electronics Corporation Oscillator, Model M-2, number R-3563. This system had a maximum voltage output of 21500 volts, due to the 1 imitations incorporated in the transformer.

The electrodes were connected to the power supply and the high voltage at a selected frequency was applied across the chamber. The voltage was monitored by a voltmeter because fluctuations in voltage could result from an etchant leak.

After a selected etching time, the high voltage was turned off and disconnected. Cleanup included removal of the electrodes, drainage of the etchant, and rinsing the chamber. The foils were rinsed in distilled water and left to dry in a small glove box so that air particles would not settle on the foils during the drying process.

Potassium hydroxide (KOH) solutions (30\% by weight) were prepared for use as etchants. The hydrophilic $\mathrm{KOH}$ pellets were dissolved in distilled water, with concentration determined by titration and a $\mathrm{pH}$ scale. 
Recoil Particle Track Counting Technique.

Several methods were available for counting the fast neutron-induced recoil particle tracks. These incuded microscopic counting and counting with a microfiche reader.

A Nikon light microscope, model number 74890 , was used for track diameter measurements and recoil particle tracks were counted on a Microcard Corporation microfiche reader, Model FR-5, number 1092. One $\mathrm{cm}^{2}$ of tracks was counted at a time with the reader. The foil was placed directly under the light and projected onto the screen at a magnification of 212 times. This method magnified the tracks enough to be easily counted and minimized the chance of counting the same track twice.

Tracks were amplified on both sides of the foil with a ratio which depends on the neutron energy and etching conditions. For consistency, tracks on both sides were counted and reported track densities were the average of 20-30 fields of view, randomly picked.

\section{Irradiation Facilities and Experimental Systems}

A11 neutron irradiations were performed at the HPRR where the polymers were exposed in air to doses ranging from 80 mrad to 50 rad for the Lexan and 1 rad for the others. The polymer sheets were supported in cardboard frames and hung parallel to the reactor core, 1.5 meters from the floor, and at distances of one to three meters, depending on the desired dose. The power level of the reactor was 40 watts for times ranging from 76 seconds to 400 seconds, also dependent on desired dose. 


\section{Leakage current measurement instrumentation}

Two electrochemical etching chambers were used in this experiment, each one holding six $250 . \mu \mathrm{m}$ thick Lexan foils. One set of unirradiated foils in one chamber and one set of irradiated (50 rads.) foils in the other were used to measure the difference in leakage current passing through the two sets of foils.

An amplifier was designed and constructed at the DOSAR to amplify the difference in leakage current between the two cells by a factor of ten. This amplifier was used in conjunction with the power supply and oscillator originally used for etching. The design, as shown in Figure 2, was a differential system to automatically subtract background and read on a voltmeter a net difference in leakage current between the two cells.

\section{Shielding experimentation}

In addition to the fission neutron spectrum obtained from the unshielded reactor, spectra behind a Lucite shield, $12 \mathrm{~cm}$ thick and $282 \mathrm{~cm}$ high, and a steel shield, $13 \mathrm{~cm}$ thick and $213 \mathrm{~cm}$ high, were used to examine the response of the Lexan and Transilwrap polycarbonates.

The Lexan polycarbonate was suspended at three meters from the core with a shield at two meters. The Transilwrap polycarbonate was placed on salt-water-filled phantoms at three meters with a shield at two meters.

The calculated spectra for the conditions of no shield, Lucite shield at two meters and steel shield at two meters are shown in Figure 3. The Lucite shield moderated the higher energy neutrons while the steel shield tended to produce a more structured spectrum with a broad peak in the 0.01-1.0 MeV range. 


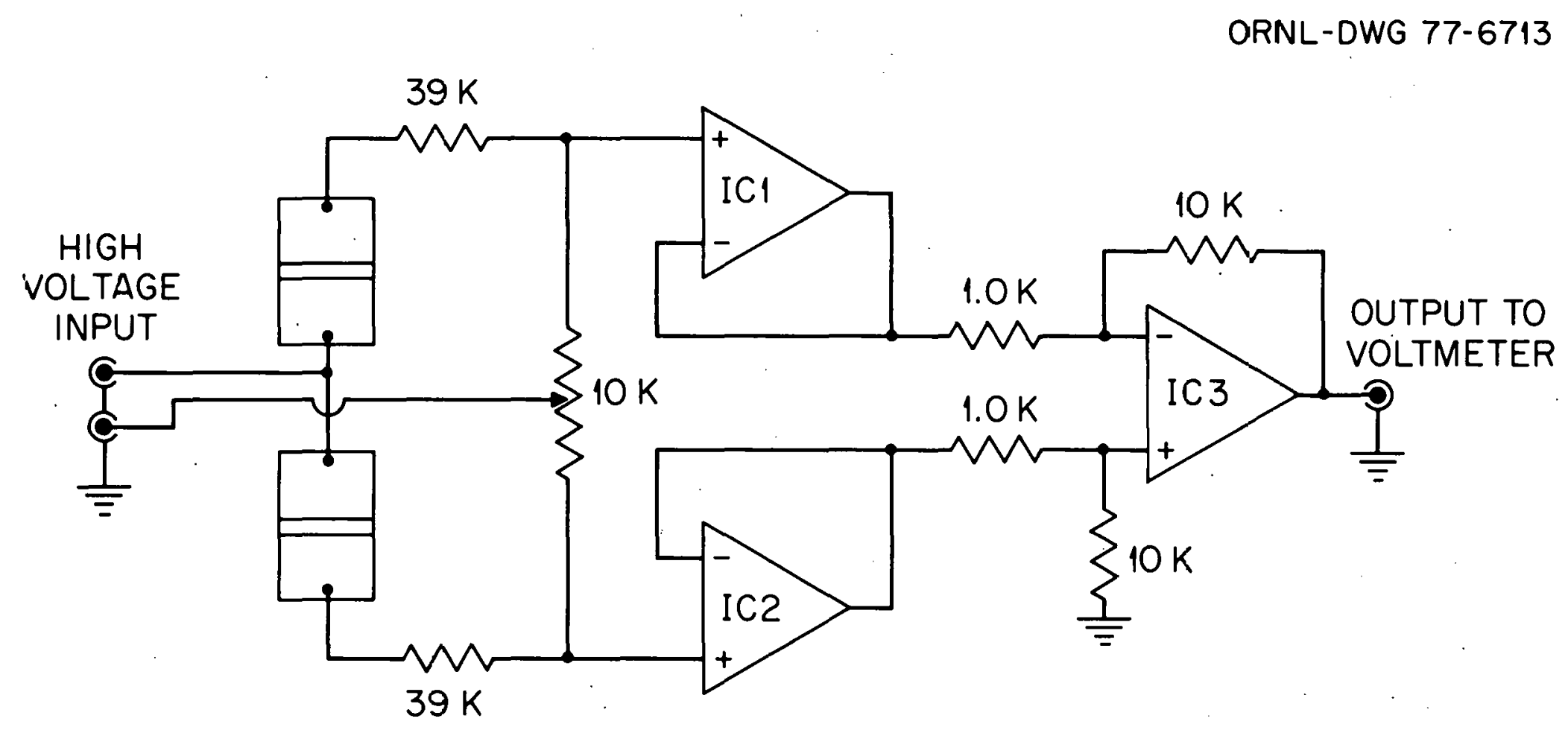

$$
\text { IC1-3 } \equiv \mu \text { A741 OPERATIONAL AMPLIFIER }
$$

Fig. 2. Schematic Diagram of Current Amplifier. 


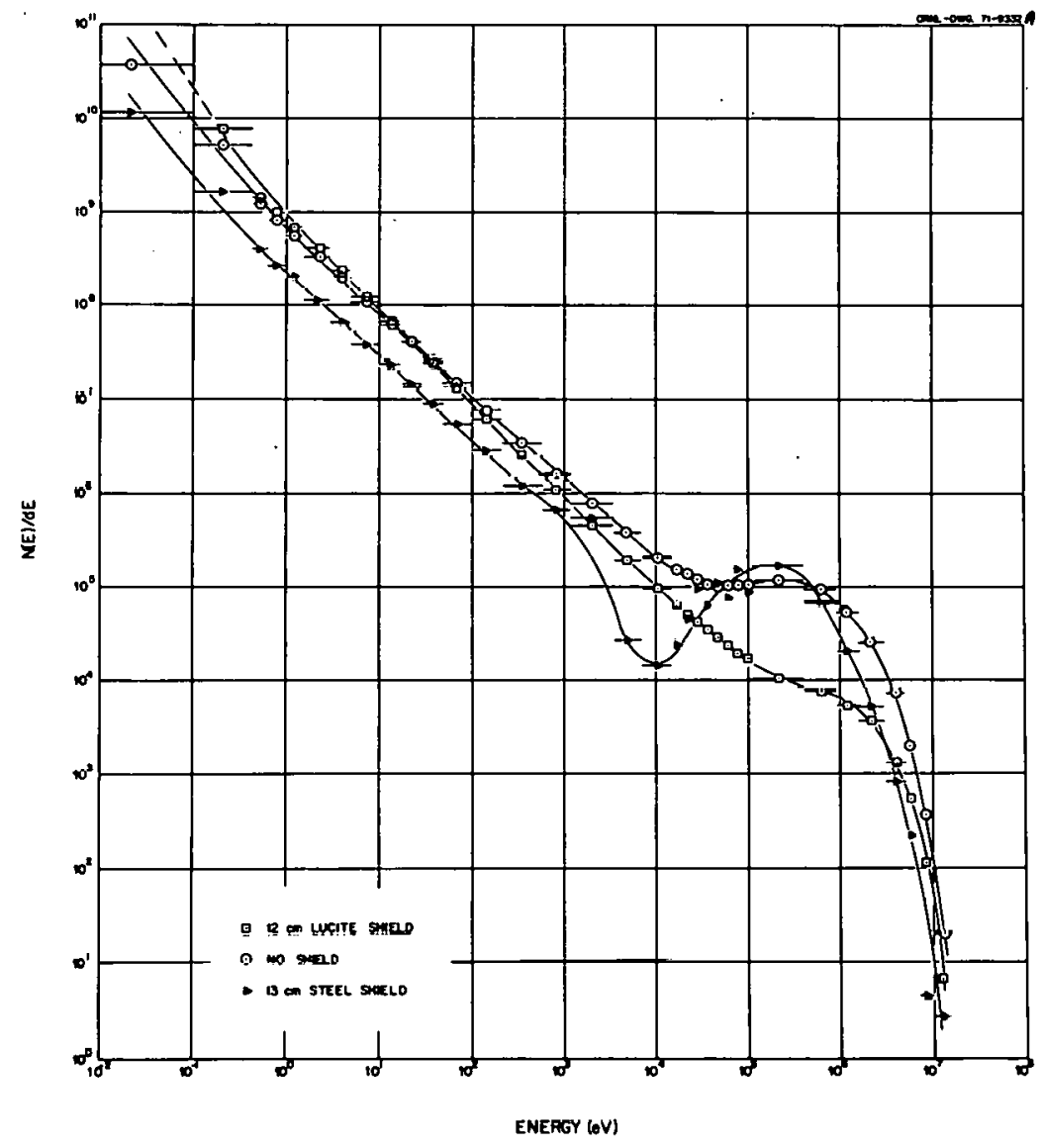

Fig. 3. Calculated Neutron Spectra at Three Meters for the HPRR. 
RESULTS AND DISCUSSION

In this study, cellulose acetate, cellulose triacetate, cellulose acetobutyrate, and polycarbonate were examined regarding their recoil particle track registration and enhancement capabilities using the electrochemical etching technique. Optical and scanning electron microscopy was employed to display the track appearance in each polymer. The effects of temperature and differing neutron spectra were investigated for polycarbonate foils.

\section{Effect of Polymer Type on Track Appearance}

Track registration and electrochemical etching depend on several factors which vary from one polymer to another. These factors include molecular composition, mechanical and electrical properties, and water absorptivity during the etching process. Table 1 compares these characteristics for each polymer.

Voltage and frequency are the keys to electrochemical etching enhancement of recoil particle tracks. The electrical properties of these polymers (their ability to withstand the stresses from the high voltages and frequencies) are very important. The etching chamber also introduces some stress on the foils during etching in the form of mechanical stress. The pressure introduced to the foils while positioned between the chamber halves becomes critical if the polymer is mechanically weak.

In the following sections, the effect of these properties on the electrochemical etching of each of the four polymers is discussed. 
Table 1. Properties of Commercial Plastics

\begin{tabular}{|c|c|c|c|c|}
\hline Polymer & $\begin{array}{c}\text { Average } \\
\text { Tensile Strength } \\
\text { (psi) }\end{array}$ & $\begin{array}{l}\text { Dielectric } \\
\text { h Strength } \\
\text { (volts/mil) }\end{array}$ & $\begin{array}{c}\text { Volume } \\
\text { Resistivity } \\
\text { (ohm-cm) } \\
\end{array}$ & $\begin{array}{l}\text { Water } \\
\text { Absorptivity } \\
(\% \text { in } 24 \mathrm{hrs})\end{array}$ \\
\hline $\begin{array}{l}\text { Celluiose } \\
\text { Acetate }\end{array}$ & $\sim 6550$ & $\sim 500$ & $10^{13}$ & $2-7$ \\
\hline $\begin{array}{l}\text { Celluiose } \\
\text { Triacetate }\end{array}$ & $\sim 7000$ & $\sim 300$ & $210^{14}$ & $2-4$ \\
\hline $\begin{array}{l}\text { Cellulose } \\
\text { Acetobutyrate }\end{array}$ & $\sim 5900$ & $\sim 400$ & $10^{12}$ & $1-2$ \\
\hline Polycarbonate & 7500 & 1500 & $10^{16}$ & $0.15-0.35$ \\
\hline
\end{tabular}

\section{Cellulose acetate}

Cellulose acetate foils of $762 \mu \mathrm{m}$ thickness were irradiated to a dose of one rad of fission neutrons and etched under the standard etching conditions used in this research of $1000 \mathrm{~V}$ and $1000 \mathrm{~Hz}$ in a $30 \%$ potassium hydroxide $(\mathrm{KOH})$ by weight solution for four hours. After etching, examination of the tracks showed them to be quite irregular in shape (Figure 4). Scanning electron microscopy showed the recoil tracks as slight depressions in the surface with a small rise at the track center (Figure 5).

To investigate further the nonuniform degradation in cellutose acetate, another set of irradiated foils was etched, this time for eight hours. Microscopic examination revealed the surface as having a sponge-like texture (Figure 6). Track identity was lost. This irregularity in the foil.surface was probably due to cellulose acetate's high absorptivity for water, as indicated in Table 1. This obvious disadvantage has rendered cellulose acetate unsuitable for use as a personnel dosimeter. 


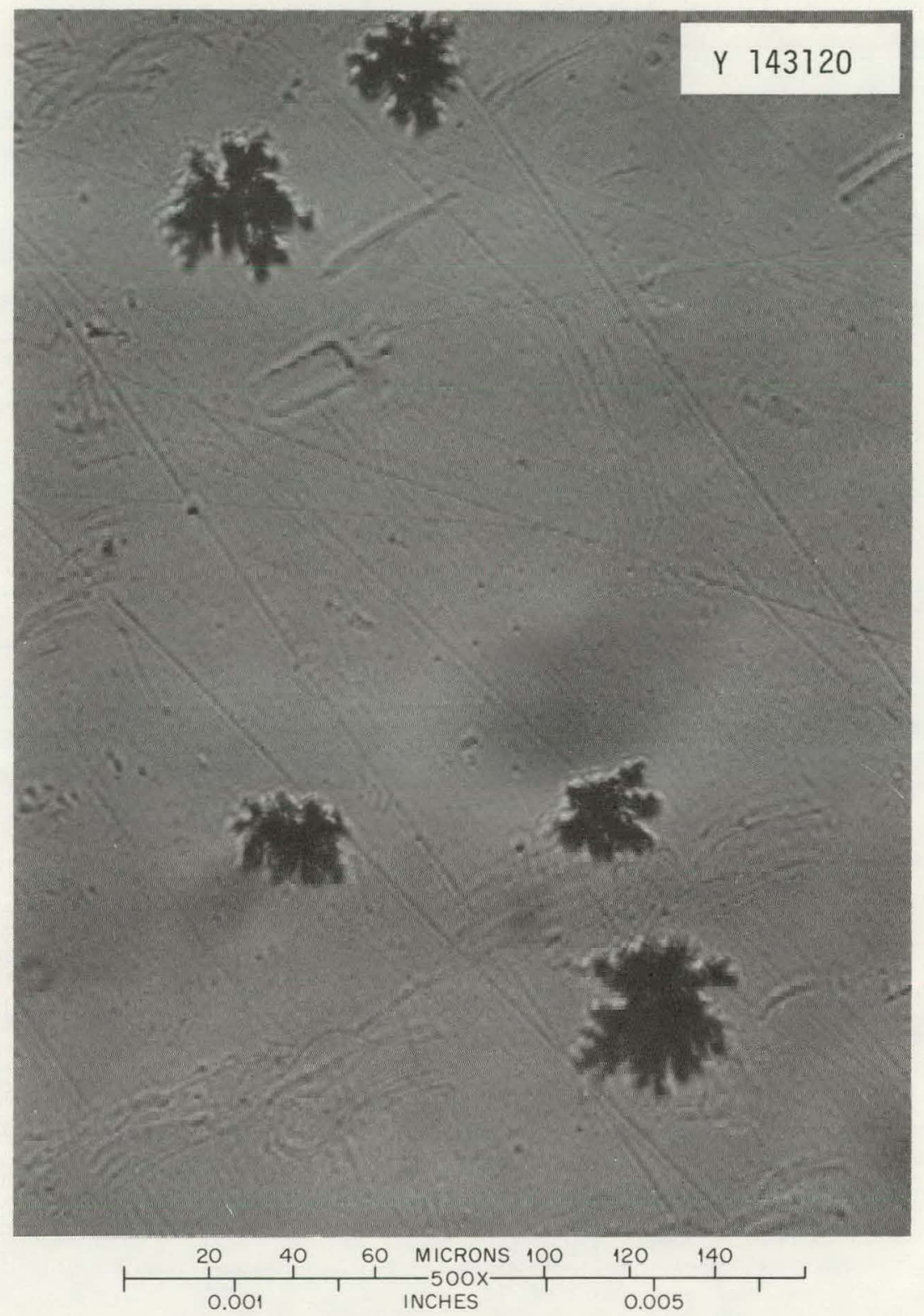

Fig. 4. Optical Micrograph of Fast Neutron-Induced Recoil Particle Tracks in $762 \mu \mathrm{m}$ Thick Cellulose Acetate, Electrochemically Etched for Four Hours in $30 \% \mathrm{KOH}$ at $1000 \mathrm{~V}$ and $1000 \mathrm{~Hz}$ (500X). 


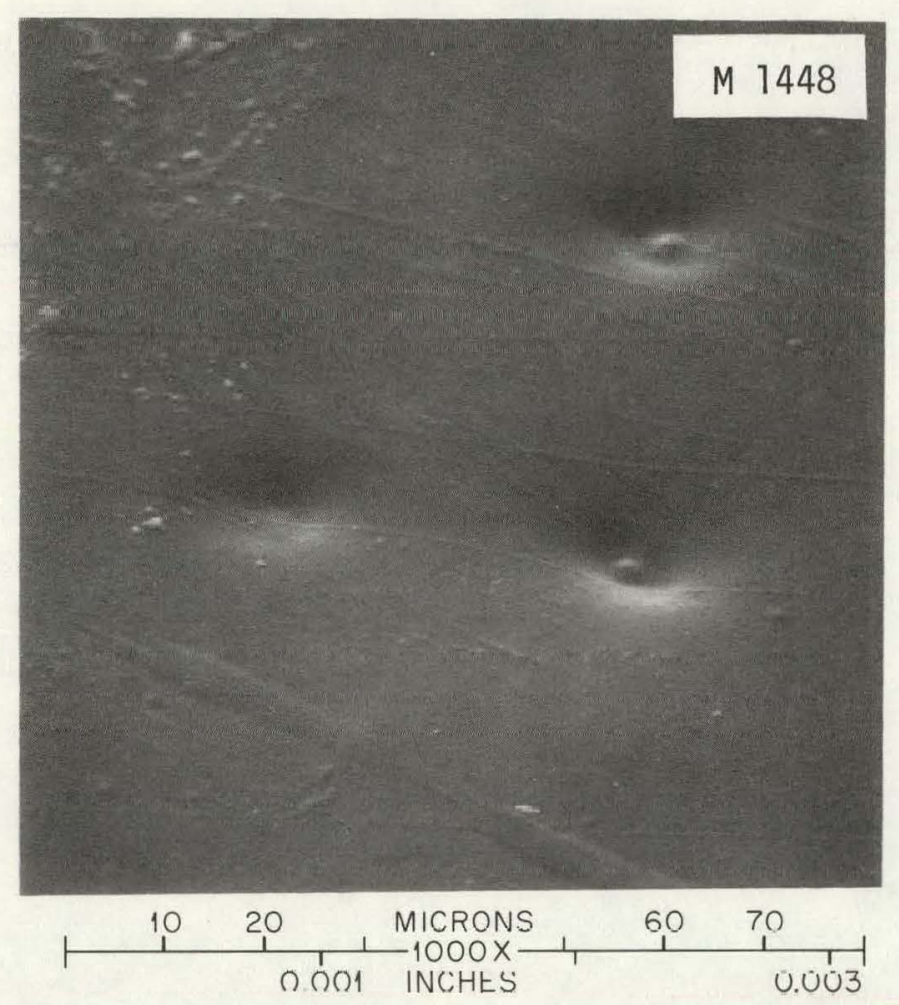

Fig. 5 Scanning Electron Micrograph of Recoil Particle Tracks in $762 \mu \mathrm{m}$ Thick Cellulose Acetate, Etched for Four Hours in $30 \% \mathrm{KOH}$ at $1000 \mathrm{~V}$ and $1000 \mathrm{~Hz}(1000 \mathrm{X})$. 


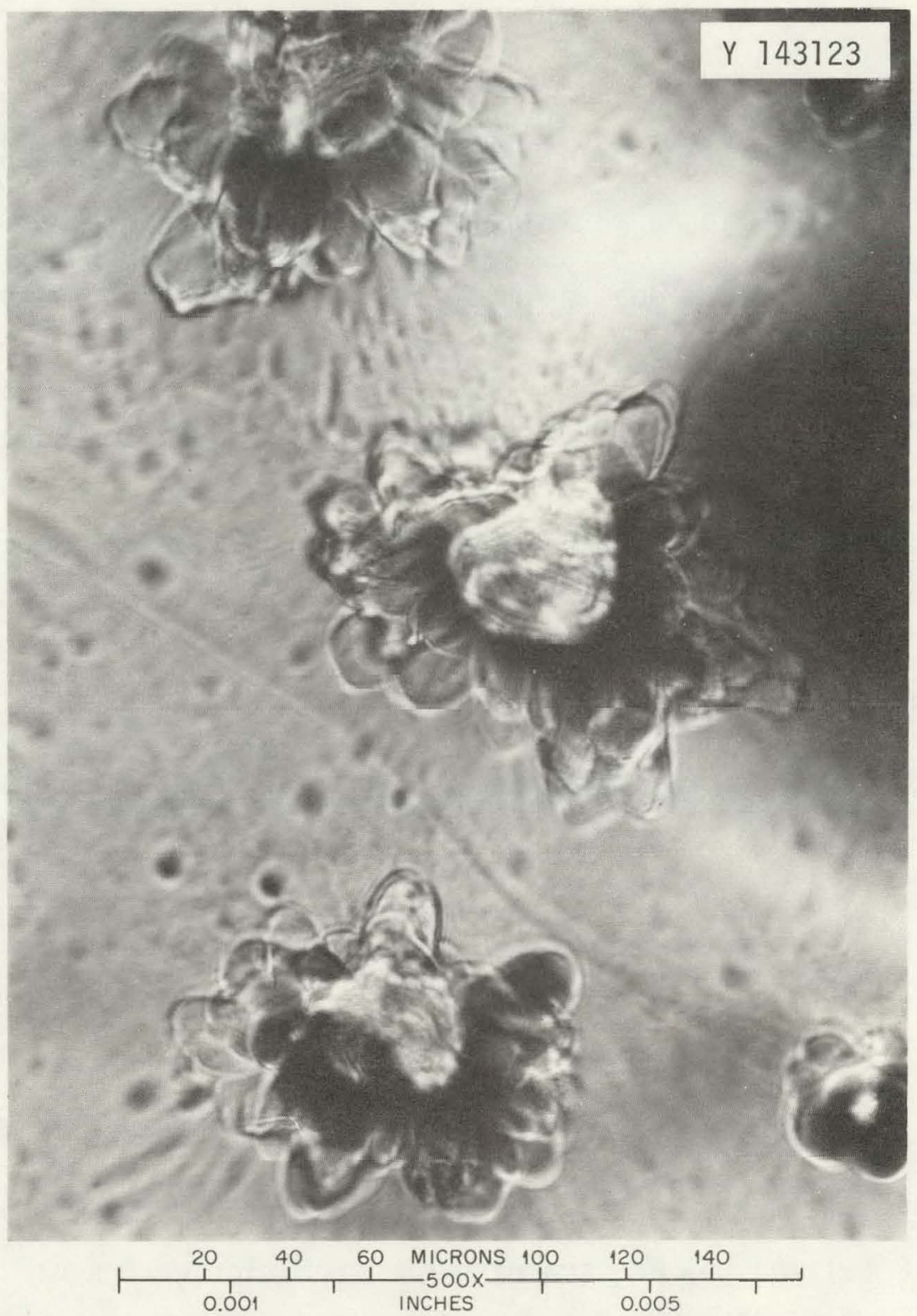

Fig. 6 Optical Micrograph of Recoil Particle Tracks in $762 \mu \mathrm{m}$ Thick Cellulose Acetate, Etched for Eight Hours in $30 \% \mathrm{KOH}$ at $1000 \mathrm{~V}$ and $1000 \mathrm{~Hz}(500 \mathrm{X})$. 


\section{Cellulose triacetate}

Cellulose triacetate foils of $250 \mu \mathrm{m}$ thickness were irradiated to 1 rad of fission neutrons and electrochemically etched under the standard etching conditions ( $1000 \mathrm{~V}, 1000 \mathrm{~Hz}, 30 \% \mathrm{KOH}$, four hours). After etching, the foil surfaces appeared cloudy, which was interpreted as an irregularity in the foil's surface due to triacetate's water absorptivity (Table 1). Though the degree of water absorption during etching was not as high as in the cellulose acetate, it was significant enough to cause problems in viewing the tracks.

Voltage and frequency values were lowered to $500 \mathrm{~V}$ and $500 \mathrm{~Hz}$, respectively, in an attempt to improve track shape. The degree of cloudiness was not significantly improved; however, the track size increased enough to be contrasted with the surrounding undamaged areas of the foil. This was most likely a result of a decrease in electrical stress on the foil at lower voltages and frequencies. Table 1 shows triacetate's dielectric strength to be lower than the other polymers examined. Figure 7 is an optical micrograph of recoil tracks as they appear in this polymer when etched at $500 \mathrm{~V}$ and $500 \mathrm{~Hz}$. Contrast is far from excellent but tracks can be distinguished from the surrounding areas. Figures 8 (a) and (b) are scanning electron micrographs of the tracks, which appear to originate as slight depressions in the foil.

It is suggested that, provided the cellulose triacetate is etched at lower voltages and frequencies, the effect of the waterbased etching solutions can be overcome. No attempt was made in this research to evaluate, in detail, triacetate as a fast neutron personnel dosimeter. 


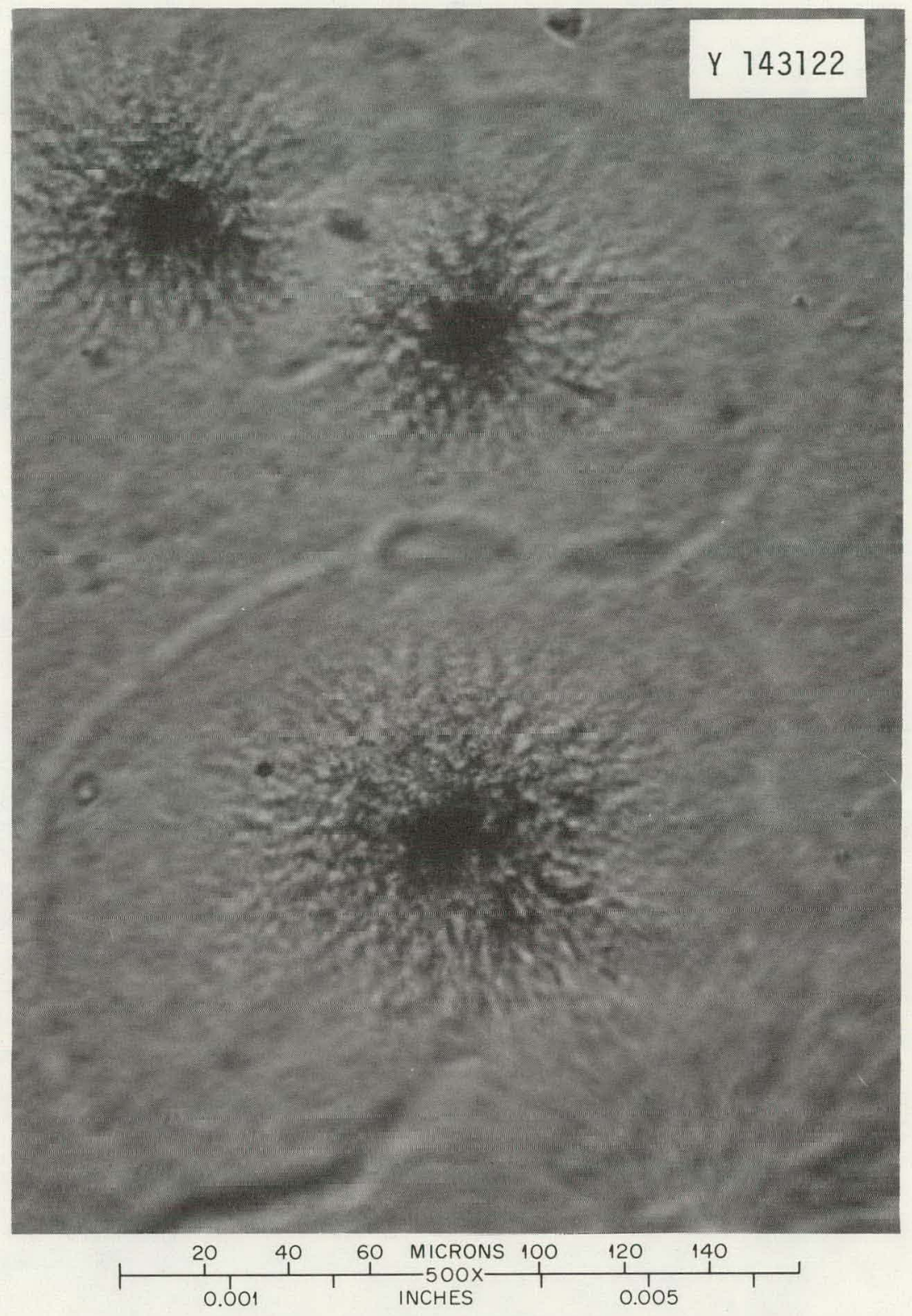

Fig. 7 Optical Micrograph of Recoil Particle Tracks in $250 \mu \mathrm{m}$ Thick Cellulose Triacetate, Etched for Four Hours in $30 \% \mathrm{KOH}$ at $500 \mathrm{~V}$ and $500 \mathrm{~Hz}$ (500X). 

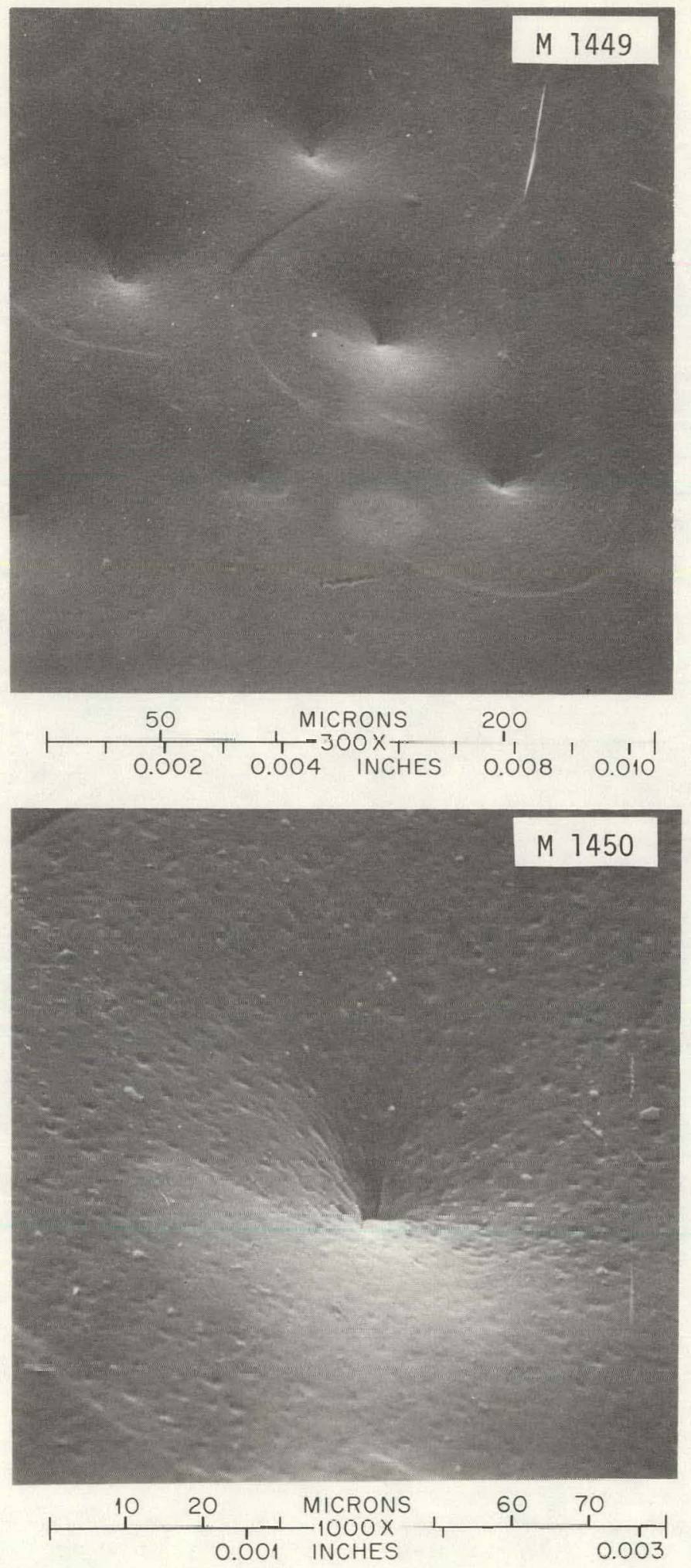

Fig. 8 Scanning Electron Micrographs of Recoil Particle Tracks in $250 \mu \mathrm{m}$ Thick Cellulose Triacetate, Etched for Four Hours in $30 \% \mathrm{KOH}$ at $500 \mathrm{~V}$ and $500 \mathrm{~Hz}$, magnified at (a) $300 \mathrm{X}$, and (b) 1000X. 


\section{Cellulose acetobutyrate}

The acetobutyrate foils ( $250 \mu \mathrm{m}$ thick) were irradiated to a dose of 1 rad of fission neutrons and etched under the standard etching conditions ( $1000 \mathrm{~V}, 1000 \mathrm{~Hz}, 30 \% \mathrm{KOH}$, four hours). After only one hour of etching, however, leaks developed and, subsequently, etching stopped. Examination of the foils revealed large cracks in the polymer. Repeated attempts produced the same results.

The voltage and frequency were reduced to 500 volts and $500 \mathrm{~Hz}$ in an attempt to alleviate whatever electrical stress may have been introduced at $1000 \mathrm{~V}$ and $1000 \mathrm{~Hz}$. Cracks again developed but did not fully penetrate the foil. This allowed the etching to proceed for the full four hours. Microscopic examination revealed the cracks in relation to the recoil tracks (Figure 9). In his investigation of electrochemically etching alpha particle tracks in this polymer, Ashraf (1976) discovered that below $400 \mathrm{~Hz}$, cracks failed to develop.

Table 1 shows cellulose acetobutyrate as having relatively low electrical properties, particularly volume resistivity, compared to the other three polymers. This explained the electrical stress at higher frequencies. Table 1 also shows the açetobutyrate as being somewhat mechanically weak (a low tensile strength). When placed between the chamber halves, the foils experienced some mechanical pressure. The cracking was thus attributed to the combination of electrical and mechanical stresses.

Figure 10 is a scanning electron micrograph of a recoil track in cellulose acetobutyrate. The tracks appeared as slight depressions in the foil surface much like those in cellulose acetate. 


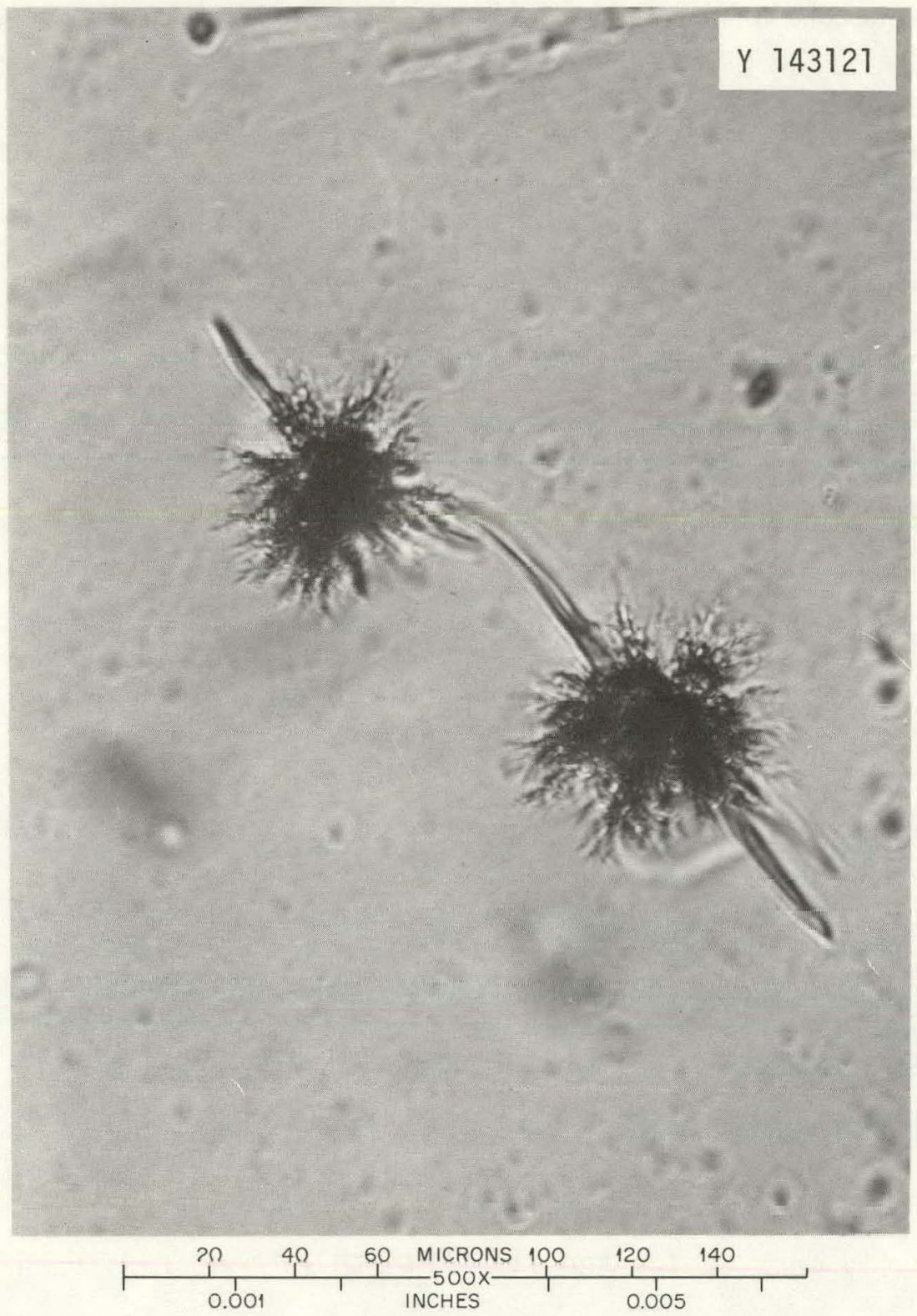

Fig. 9 Optical Micrograph of Recoil Particle Tracks in $250 \mu \mathrm{m}$ Thick Celluluse Acetobutyrate, Etched for Four Hours in $30 \% \mathrm{KOH}$ at $500 \mathrm{~V}$ and $500 \mathrm{~Hz}(500 \mathrm{X})$. 


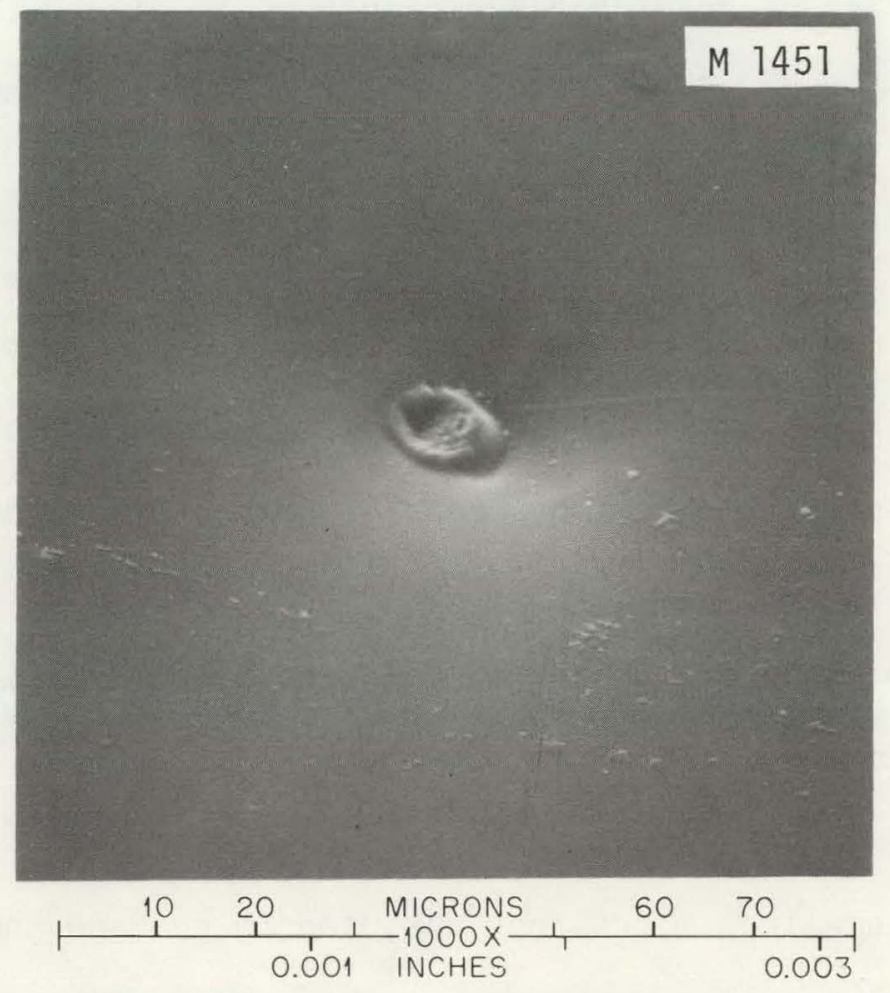

Fig. 10 Scanning Electron Micrograph of a Recoil Particle Track in $250 \mu \mathrm{m}$ Thick Cellulose Acetobutyrate, Etched for Four Hours in $30 \% \mathrm{KOH}$ at $500 \mathrm{~V}$ and $500 \mathrm{~Hz}$ (1000X). 


\section{Polycarbonate}

Lexan polycarbonate of $250 \mu \mathrm{m}$ thickness was irradiated with fission neutrons in doses of $80 \mathrm{mrad}, 150 \mathrm{mrad}, 400 \mathrm{mrad}, 1 \mathrm{rad}$, and 50 rads to show that a trained eye could estimate doses to personnel when a set of standard irradiated-and-etched foils such as in Figure is used for comparison purposes. These foils were etched for four hours in $30 \% \mathrm{KOH}$ at $1000 \mathrm{v}$ and $1000 \mathrm{~Hz}$.

Polycarbonate has excellent mechanical, electrical, and water absorptivity properties as compared to the cellulose derivatives examined. Optical micrographs showed the recoil particle tracks to be very uniform (round) in shape with excellent contrast against the undamaged areas of the foil (Figure 12). Track size distribution varied (Figure 13) due to the energy and angle of incidence of the neutrons as well as the etching conditions. As etching time increased, more of the foil surface was etched away, revealing subsurface recoil tracks.

Scanning electron microscopy was used to examine the tracks in Lexan and compare their appearance to those in another polycarbonate, Transilwrap by Tuffak, Inc. Figures 14 and 15 represent the Transilwrap and Lexan respectively. The etch pits in the Transilwrap appeared much like those in the cellulose derivatives. The track center originated as a depression in the surface, but with the surrounding area being etched away from the center to eventually form a definite circular-shape track. The etch pits in Lexan, on the other hand, seemed to be etched in stages, originating at the track center and extending at regular intervals symmetric to the center until they reached maximum diameter (or until the etching procedure was stopped). Optical microscopy displayed 


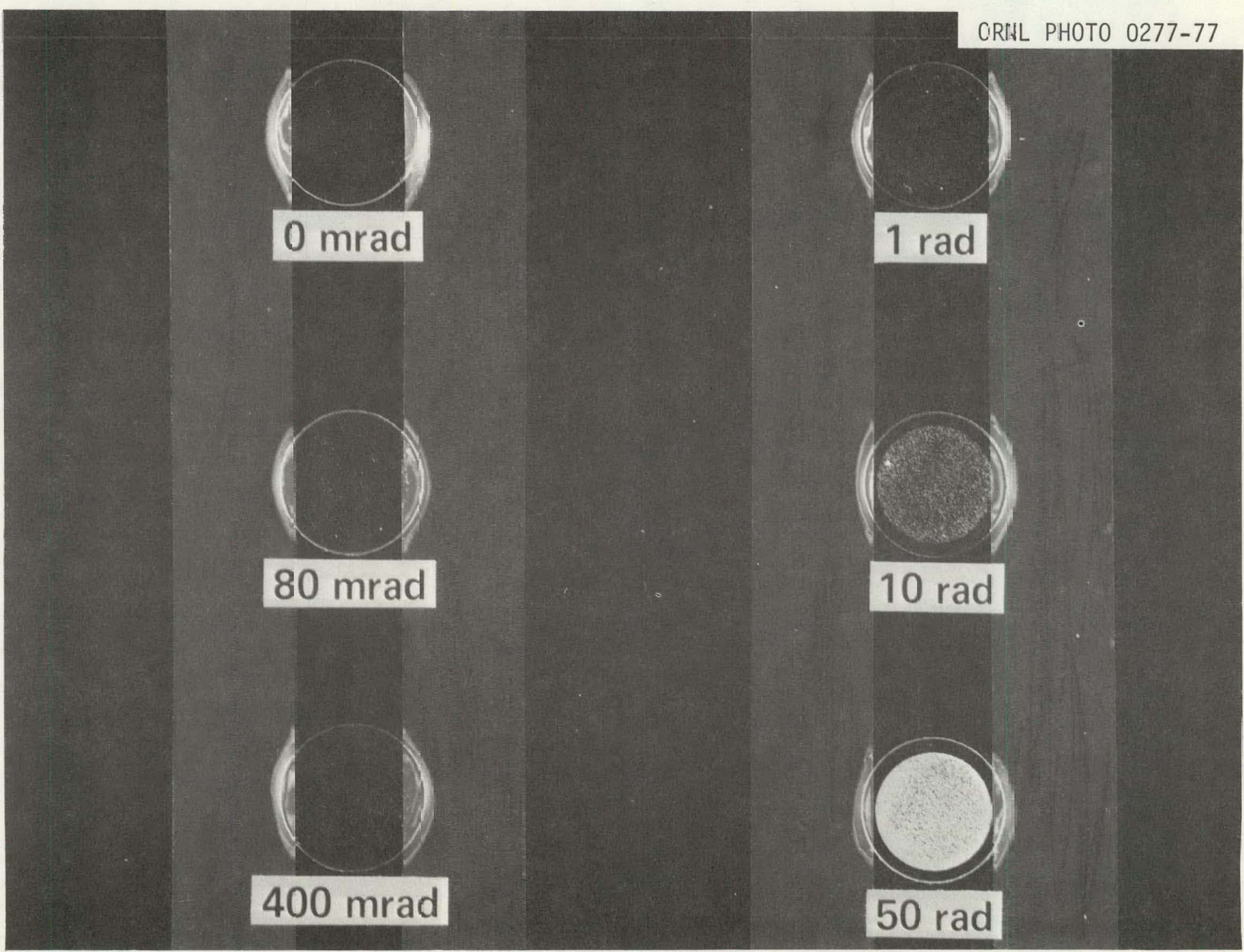

Fig. 11. Photograph of Recoil Particle Tracks in $250 \mu \mathrm{m}$ Thick Lexēn Exposed to $\mathrm{Di}=$ ferent Doses of Fission Neutrons from the HPRR, Etched $\Rightarrow, j$ Four Hours in $30 \% \mathrm{KOH}$ at $1000 \mathrm{~V}$ and $1000 \mathrm{~Hz}$. 


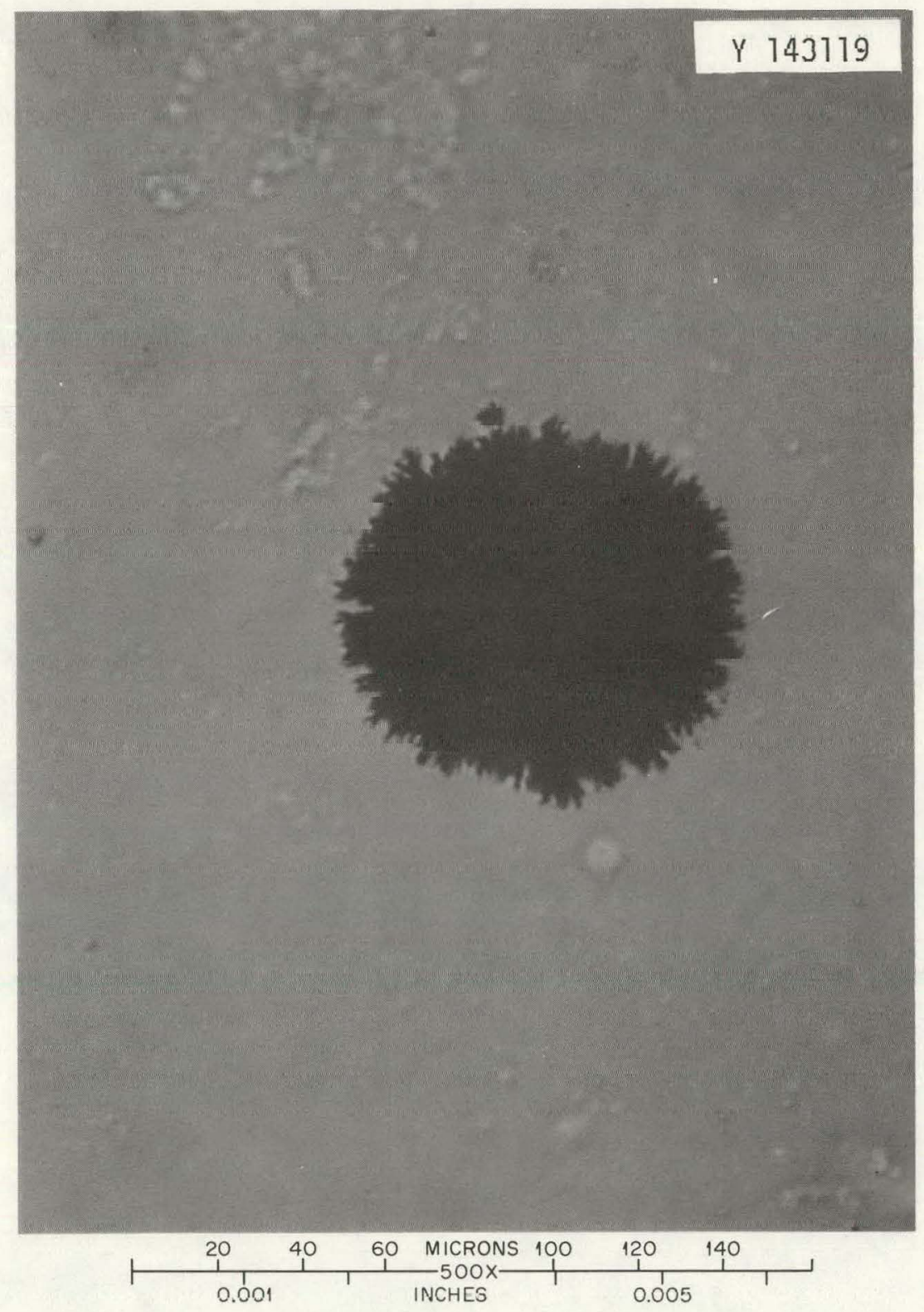

rig. 12. Uptical Micrograph of a Recoil Particle Track in $250 \mu \mathrm{m}$ Thick Lexan Etched for Four Hours in $30 \% \mathrm{KOH}$ at $1000 \mathrm{~V}$ and $1000 \mathrm{~Hz}$ (500X). 


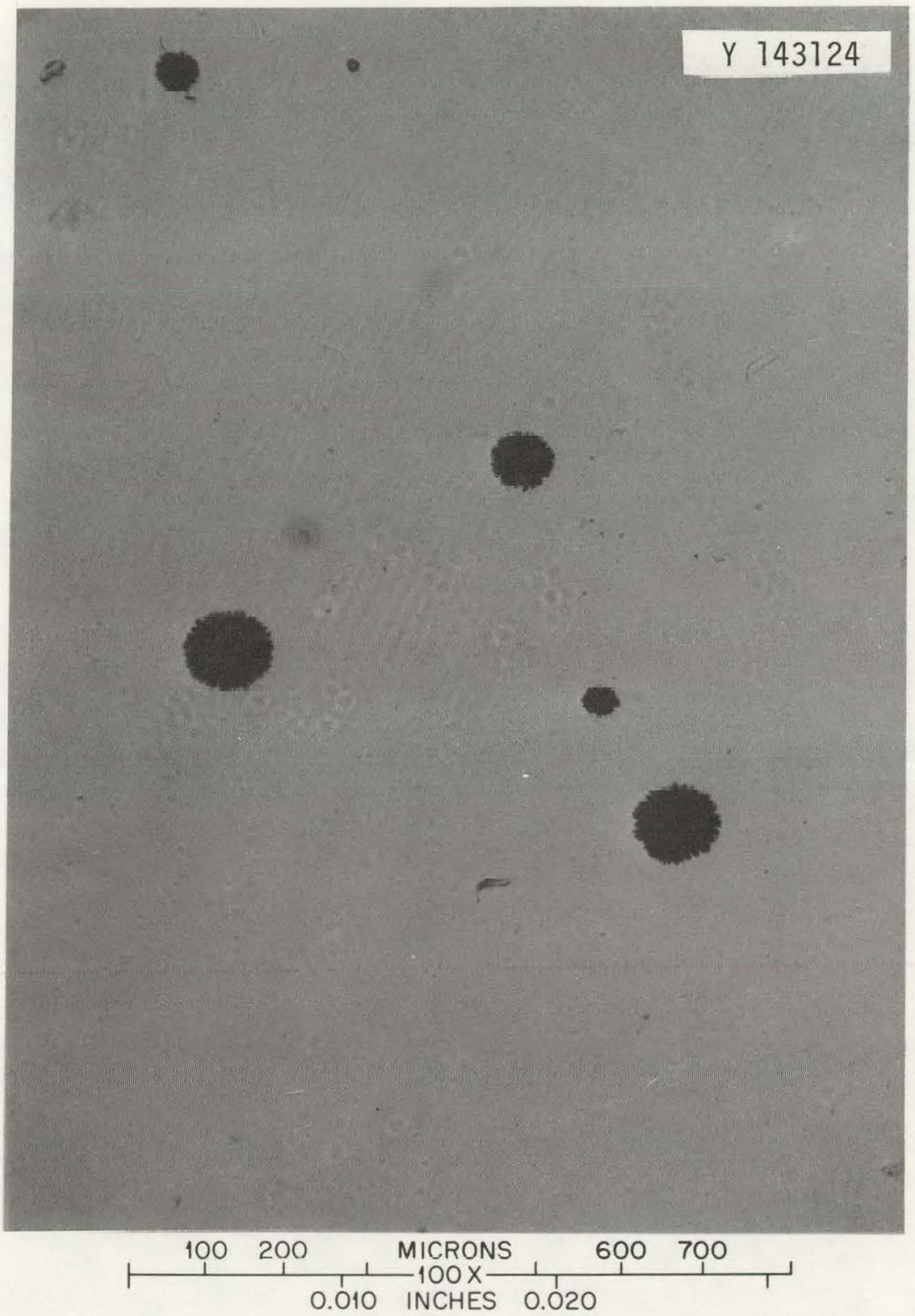

Fig. 13. Optical Micrograph of Recoil Particle Track Size Distribution in $250 \mu \mathrm{m}$ Thick Lexan Etched for Four Hours in $30 \% \mathrm{KOH}$ at $1000 \mathrm{~V}$ and $1000 \mathrm{~Hz}(100 \mathrm{X})$. 


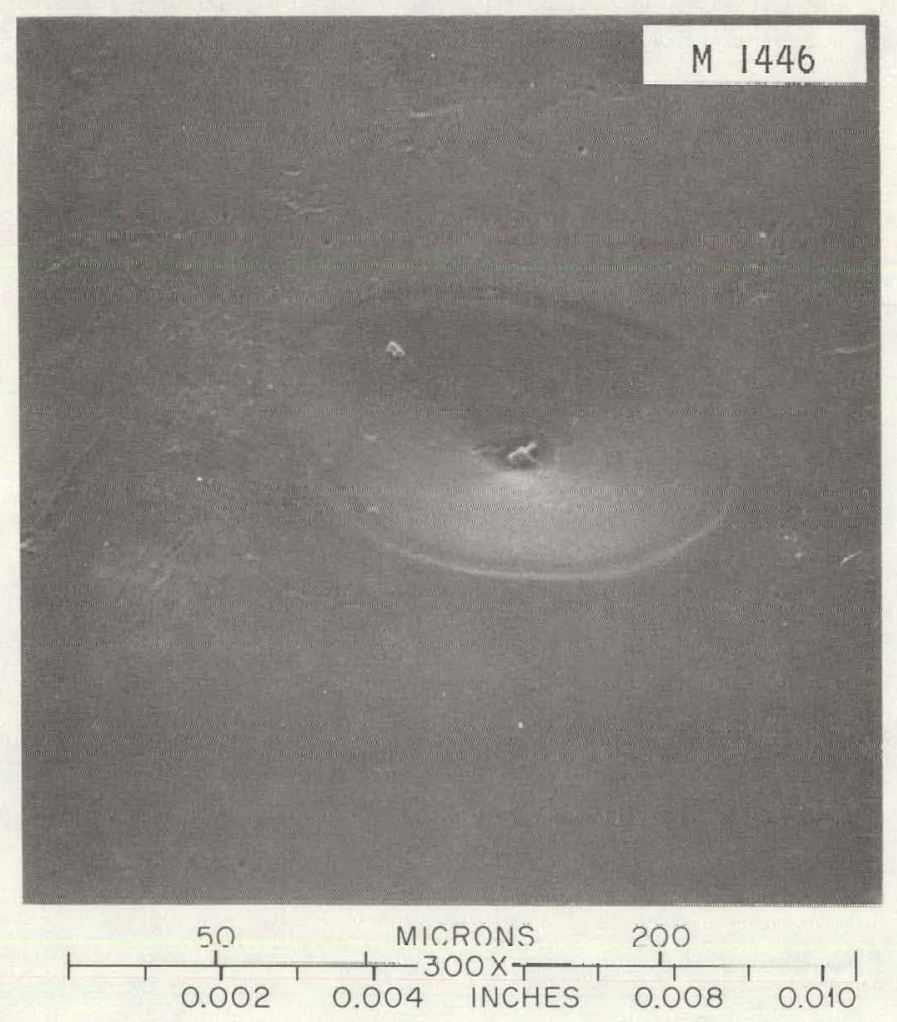

Fig. 14. Scanning Electron Micrograph of a Recoil Particle Track in $250 \mu \mathrm{m}$ Thick Transilwrap Etched for Four Hours in 30\% $\mathrm{KOH}$ at $1000 \mathrm{~V}$ and $1000 \mathrm{~Hz}$ (300X). 


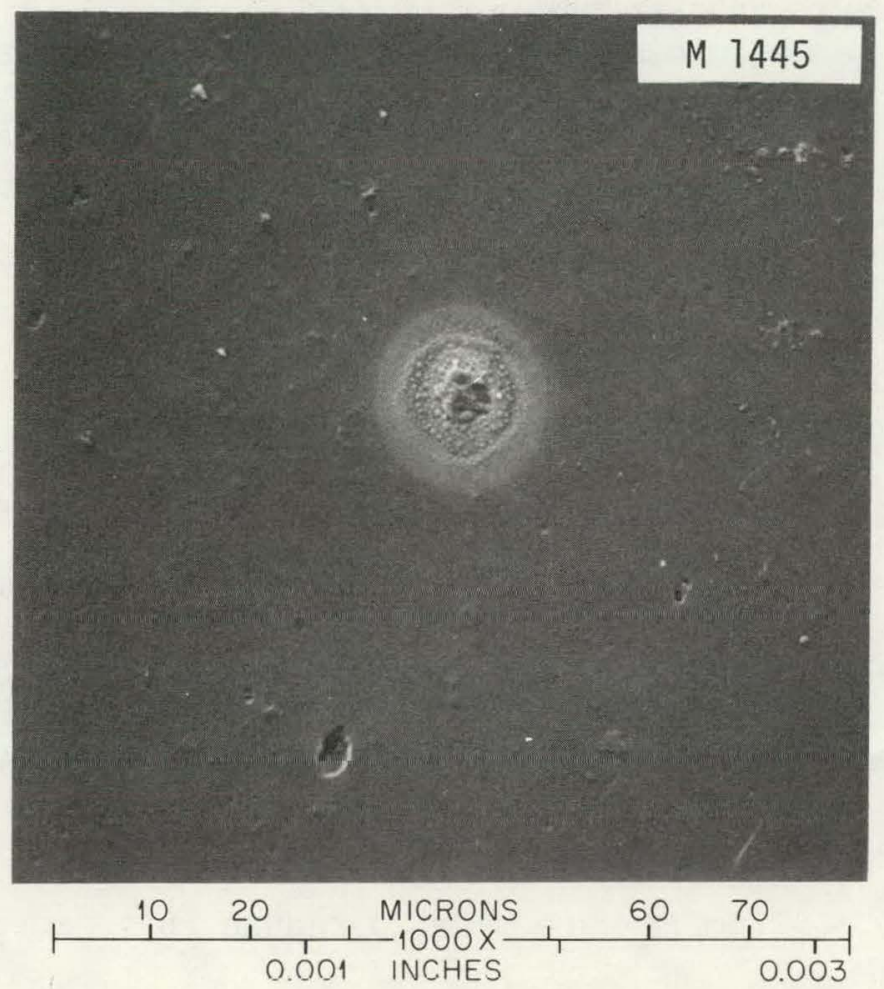

Fig. 15. Scanning Electron Micrograph of a Recoil Particle Track in $250 \mu \mathrm{m}$ Thick Lexan Etched for Four Hours in $30 \% \mathrm{KOH}$ at $1000 \mathrm{~V}$ and $1000 \mathrm{~Hz}(1000 \mathrm{X})$. 
a recoil track as a large "hole" in the foil surface (Figure 12) due to shadows cast by light scattered across the foil surface.

The recoil particle tracks were more uniform in shape and displayed excellent contrast against the undamaged areas in polycarbonate as compared to the cellulose derivatives examined. Polycarbonate is superior to the other polymers in terms of electrical and mechanical strength and does not suffer from high water absorptivity.

\section{Effect of Storage Temperature on Lexan}

Unknown neutron doses can be readily estimated by a trained eye when compared to a standard set of irradiated and etched foils as shown in Figure 11. For low doses (1ess than $2150 \mathrm{mrad}$ ), however, a polycarbonate with a low background track density is necessary for dose estimations such as these. The Lexan polycarbonate studied in this research was supplied as sample sheets (age unknown) which had a high background track density. Attempts were made to reduce this background by annealing and the results are discussed in this section.

The fading of recoil tracks is another important factor when considering these detectors as personnel dosimeters. If stable with regards to temperature, dosimeters may be kept as permanent records of doses received. This fading as a function of temperature is also discussed in this section.

\section{Effect on background track density}

Unirradiated Lexan fuils (250 $\mathrm{mm}$ thick) were annealed at $100^{\circ} \mathrm{C}, 120^{\circ} \mathrm{C}$, and $140^{\circ} \mathrm{C}$ for times extending to 24 hours and were subsequently etched at $1000 \mathrm{~V}$ and $1000 \mathrm{~Hz}$ for four hours in $30 \% \mathrm{KOH}$. The results are shown in Figure 16. The average background track density for unirradiated, 


\section{ORNL-DWG 77-11999}

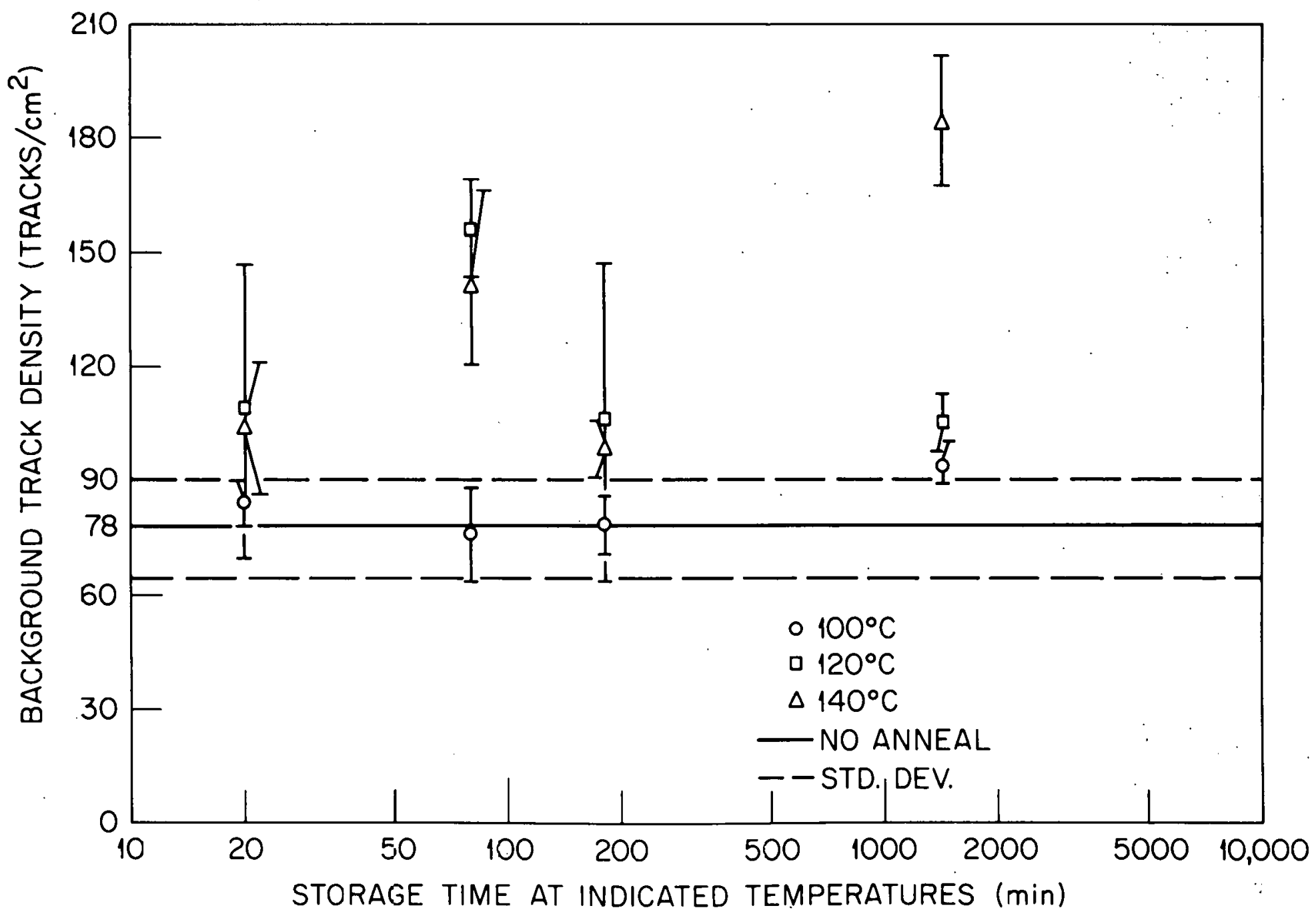

Fig. 16 Background Track Density as a Function of Time at Indicated Temperatures. 
unannealed foils was $78 \pm 14 \mathrm{tracks} / \mathrm{cm}^{2}$. Annealing the foils failed to reduce this background. In fact, after 24 hours at $140^{\circ} \mathrm{C}$, the track density increased substantially.

A telephone conversation with Mr. Herb Curry of General E.lectric (Curry, 1977) revealed some interesting information regarding temperature effects on Lexan. At $135^{\circ} \mathrm{C}$, only surface anneal occurs. At temperatures below $155^{\circ} \mathrm{C}$, thermomechanical stresses are introduced into the polymer. This may tend to increase the number of artifact "tracks" that appear in the unirradiated foils. Rearrangement of molecular structure occurs after only five minutes at $151^{\circ} \mathrm{C}$, also resulting in artifact "tracks".

\section{Effect on recoil particle track density}

Lexan foils were irradiated to a dose of one rad of fission neutrons. Fading of the resultant recoil particle tracks was examined at $60^{\circ} \mathrm{C}$, $100^{\circ} \mathrm{C}, 120^{\circ} \mathrm{C}$, and $140^{\circ} \mathrm{C}$. The results are shown in Figure 17 . Unannealed, unirradiated foils were used as controls to determine background track densities.

Recoil tracks remained stable at $60^{\circ} \mathrm{C}$ but began to fade rapidly at $100^{\circ} \mathrm{C}$. Annealing at $120^{\circ} \mathrm{C}$ and $140^{\circ} \mathrm{C}$ did not slgnificantly change the rate of fading. After only one hour at these temperatures, the recoil track density remained significantly above the background because of the increase in normal barkground resulting from prolonged storage above $100^{\circ} \mathrm{C}$. Temperatures normally encountered by personnel are not this high. It can, therefore, be assumed that these dosimeters are stable regarding fading of the recoil tracks under normal usage. 




Fig. 17. Recoil Particle Track Density as a Function of Time at Indicated Temperatures. 


\section{Differential Leakage Current Measurement}

Two sets of Lexan foils, one unirradiated and one irradiated to a dose of 50 rads of fission neutrons, were used to measure leakage current in a conducting but nonetching salt solution. The objective was to determine a frequency where leakage current difference between the undamaged and damaged foils was at a maximum, possibly indicating the frequency where track enhancement was the greatest.

Figure 18 shows the leakage current in terms of voltage for the undamaged and the highly damaged folls as the frequency was increased in increments of $100 \mathrm{~Hz}$. The fact that there is a non-zero effect with the undamaged foils is caused by a slight circuit mismatching. As expected, the amount of leakage current that passed through the damaged foils was greater, especially between $1000 \mathrm{~Hz}$ and $2000 \mathrm{~Hz}$. This frequency range was previously determined by Sohrabi as yielding optimum enhancement results (Sohrabi, 1975). Beyond $2000 \mathrm{~Hz}$, the system began to fail due to the one milliamp current limitation of the power supply.

At these high frequencies $(21800 \mathrm{~Hz})$, more current passed through the conductive regions of the foils (the recoil particle tracks) which may represent a localized heating, a possible explanation for track enhancement when polymer foils are electrochemically etched.

\section{Response to Different Neutron Sportra}

Lexan and Transilwrap foils were irradiated to doses of $100 \mathrm{mrad}$ and $50 \mathrm{mrad}$, respectively, with the bare reactor and behind the two shields. Their responses (track $/ \mathrm{cm}^{2}-\mathrm{mrem}$ ) to the three spectra shown in Fig. 3, are given in Table 2. 


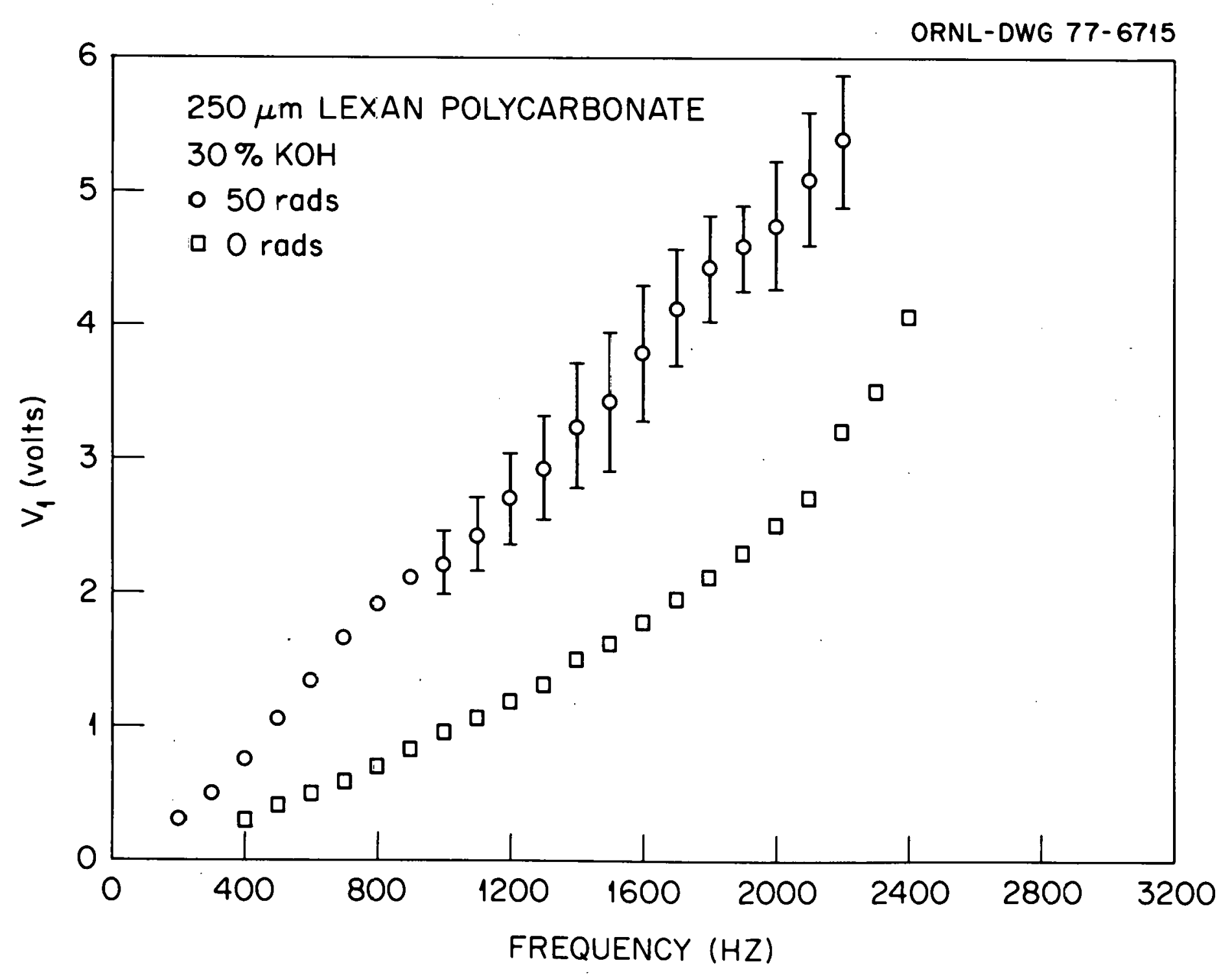

Fig. 18. Differential Leakage Current in Terms of Vortage. 
Table 2. Response of polycarbonates to different

neutron spectra from. HPRR

\begin{tabular}{|c|c|c|c|c|c|c|c|c|c|c|c|}
\hline \multirow{2}{*}{$\begin{array}{l}\text { Poly- } \\
\text { carbonate }\end{array}$} & \multirow{2}{*}{$\begin{array}{l}\text { Background } \\
\left(\text { tracksi } \mathrm{cm}^{2}\right)\end{array}$} & \multirow{2}{*}{$\begin{array}{l}\text { Cose } \\
(\text { mirad })\end{array}$} & \multicolumn{3}{|c|}{ Quali=y factor } & \multicolumn{3}{|c|}{$\begin{array}{c}\text { Recoil track dersity } \\
\text { (tracks } / \mathrm{cm}^{2} \text { : }\end{array}$} & \multicolumn{3}{|c|}{$\begin{array}{c}\text { Response } \\
\left.\text { (tracks } / \mathrm{cm}^{2}-\mathrm{mrem}\right) \\
\end{array}$} \\
\hline & & & Bare & Lucite & Steel & Bare & Lucite & Steel & Bare & Lucite & Steel \\
\hline Lexan & $78 \pm 14$ & 100 & 9.4 & 8.5 & 9.5 & $72 \pm 37$ & $34 \pm 3 i$ & $21 \div 18$ & 0.076 & 0.038 & 0.022 \\
\hline Transilwrap & $11 \pm 2$ & 50 & 9.4 & 8.9 & 9.5 & $18 \pm 8$ & $9 \pm 5$ & $17 \pm 6$ & 0.036 & 0.022 & 0.032 \\
\hline
\end{tabular}


The Lexan and Transilwrap displayed high and low background track densities, respectively. The recoil track densities in the Lexan, were very inconsistent, sometimes deviating by as much as $91 \%$, while the Transilwrap track densities remained somewhat more consistent than the Lexan.

Lexan had response ratios for bare-to-Lucite and Lucite-to-steel of $2: 1$ and $1.7: 1$, respectively. The corresponding ratios for the Transilwrap were $1.6: 1$ and $0.69: 1$.

When the various reactor spectra are considered, these variations in response ratios seemed to imply that Transilwrap responded to neutrons of lower energies than did the Lexan. Any further quantification was impossible, however, due to the large errors obtained when attempting to measure small doses. 
SUMMARY AND RECOMMENDATIONS

Summary

An electrochemical etching method was examined for enhancement of fast neutron-induced recoil particle tracks in four polymers, namely cellulose acetate, cellulose acetobutyrate, cellulose triacetate, and polycarbonate.

Irradiated polymer foils were etched under standard etching conditions of $1000 \mathrm{~V}, 1000 \mathrm{~Hz}$ in $30 \%$ (by weight) $\mathrm{KOH}$ for four hours at $25^{\circ} \mathrm{C}$. The cellulose acetate and triacetate foil surfaces became clouded, resulting in poor contrast between the tracks and the undamaged areas. Cellulose acetate foil surfaces became spongy after etching for eight hours, and track identity was lost. Water absorption properties are high for these two polymers as compared to the acetobutyrate and polycarbonate. Lowering the voltage and frequency to $500 \mathrm{~V}$ and $500 \mathrm{~Hz}$ reduced surface clouding, thus, improving contrast in the cellulose triacetate. This improvement by reducing the electrical stress on the foils was due to triacetate's low dielectric strength (as compared to the other polymers).

The cellulose acetobutyrate experienced cracking during etching. Lowering voltage and frequency to $500 \mathrm{~V}$ and $500 \mathrm{~Hz}$ reduced the depth of the cracks. Research (Ashraf, 1976) has found that cracking does not occur at frequencies below $500 \mathrm{~Hz}$. The acetobutyrate possesses a low tensile, dielectric strength, and volume resistivity. 
The polycarbonate, however, has high tensile and dielectric strengths, high volume resistivity, and very low water absorptivity. The clarity of the recoil tracks in this polymer was superior to those registered and etched in the other three. The Lexan polycarbonate has a high sensitivity to fast neutrons but also has a high background track density. Attempts to reduce this background by annealing were unsuccessful. Recoil particle tracks remained stable in the Lexan foils below $60^{\circ} \mathrm{C}$ but began to fade rapidly beyond $100^{\circ} \mathrm{C}$.

Leakage current measurements between damaged and undamaged Lexan foils revealed $1800-2000 \mathrm{~Hz}$ as the optimum frequency range for electrochemical etching. This was previously determined to produce the maximum mean track diameter, optical density, and response (tracks $/ \mathrm{cm}^{2}-\mathrm{rad}$ ) measurements (Sohrabi, 1975).

The response of Lexan and Transilwrap polycarbonates to the three standard neutron spectra of the HPRR was examined. The Lexan with a background track density of $78 \pm 14 \mathrm{tracks} / \mathrm{cm}^{2}$, yielded responses (tracks/ $\mathrm{cm}^{2}$-mrem) of 0.076 from the bare reactor, 0.038 behind the Lucite shield, and 0.022 behind the steel shield. Recoil particle track densities were very inconsistent in the Lexan. In some instances, standard deviation approached $100 \%$. The Transilwrap had a low background track density (11 $\pm 2 \mathrm{tracks} / \mathrm{cm}^{2}$ ) and responses of $0.036,0.022$, and $0.032 \mathrm{tracks} / \mathrm{cm}^{2}$ mrem to the bare, lucite-shielded, and steel-shielded reactor, respectively. These data gave some evidence to imply that Transilwrap responded to neutrons of lower energy than did the Lexan. More evidence is needed, however, to quantify a threshold neutron energy for these two polycarbonates. 


\section{Recommendations}

Polycarbonate foils show promise for neutron personnel dosimetry. Polycarbonate has a threshold energy of 21 . MeV for registering fast neutron-induced recoil particle tracks. It has high volume resistivity, dielectric and tensile strengths, and low water absorptivity. It also produces highly-contrasted, electrochemically etched tracks. Cellulose acetate and cellulose acetobutyrate, however, are known to be chemically more sensitive than polycarbonate for recording damage tracks. By selection of optimum frequencies, voltages and etching times, it may still be possible to provide a sensitive electrochemical track etch detector having a neutron energy threshold of only a few tenths of an MeV. If such a system can be developed, it could be used in conjunction with the albedo-neutron dosimeter for personnel monitoring to cover a wider range of neutron energies.

Further research development is possible in the field of electrochemical etching of polycarbonate. The frequencies found to be optimum for track enhancement in this polymer range from $1000 \mathrm{~Hz}$ to $2000 \mathrm{~Hz}$. Energy dissipation, however, does not maximize in polycarbonate until frequencies exceed $10^{6} \mathrm{~Hz}$ (Harper, 1976). Development of a power supply capable of extending the frequency range for electrochemical etching of polycarbonate into the megahertz region could produce sume interesting and possibly advantageous results for optimum enhancement of tracks in this polymer. 
Lexan, the polycarbonate used most extensively in this research, has a high sensitivity but a high background track density as well, thus hindering its ability to measure low doses. The Transilwrap was employed only as a comparative to Lexan in response to spectra examination. This polycarbonate displayed a low background track density and is currently being examined by Dick Oswald of R. S. Landauer, Inc. and Dan Christian of ORNL. Mr. Oswald recently stated (Oswald, 1977) the Transilwrap as being capable of measuring fast neutron dose equivalents of 40 上 $28 \%$ mrem when irradiated with an Am-Be source and electrochemically etched in $28 \% \mathrm{KOH}$ at $1000 \mathrm{~V}$ and $2000 \mathrm{~Hz}$. Mr. Christian has discovered the recoil particle track size and general appearance is strongly dependent on the age and concentration of the etchant. He suggests normality of the solution be used as a standard reference rather than percent by weight. This information, as research on Transilwrap develops, is most promising and should be examined further. 


\section{THIS PAGE}

WAS INTENTIONALLY

LEFT BLANK 


\section{LIST OF REFERENCES}

Ashraf, J. November 1976. Unpublished M.S. Thesis. University of Tennessee

Becker, K. 1973: Solid State Dosimetry. CRC Press. Cleveland, Ohio

Becker, K. and Razek, M. 1975. "Automatic Spark Counting of Fast Neutron-Induced Recoil Particle Tracks in Polymer Foils." Nucl. Inst. Methods. 24, 557

Cross, W. G. and Tommasino, L. 1970. "Rapid Reading Technique for Nuclear Particle Damage Tracks in Thin Foils." Rad. Effects. $\underline{5}, 85$

Curry, Herb. January 1977. General Electric. Personal communication.

Fleischer, R. L., Price, P. B., and Walker, R. M. 1975. Nuclear Tracks in Solids. University of California Press. Berkley, California

Griffith, R. V. 1976. Personnel Monitoring Measurements. Lawrence Livermore Laboratory. UCRL - 77816

Hankins, D. C. 1973. "Progress in Personnel Neutron Dosimetry" in Proceedings of Third International Congress of IRPA. Washington, D. C. Conf-730907

Harper, C. A. 1976. "Insulate with Plastics and Elastomers." Elect. Design. 13, 8694

Jasaik, J. and Piesch, E. 1975. "Automatic Spark Counting of Neutron-Induced Recoil Tracks in Polycarbonate Foils." Nucl. Inst. Methods: 128, 447-453

Johnson, D. R. and Becker, K. 1970. Mechanisms and Applications of Nuclear Track Registration in Polymers. Oak Ridge National Laboratory ORNL/TM-2826

Jozefowicz, K. 1971. "Energy Dependence of the Efficiency of Neutron Detection in Polycarbonate by Recording Atom Recuil Tracks." Nucl. Inst. Methods. 93, 369

Katz, R. and Kobetich, E. J. 1968. "Formation of Etchable Tracks in Dielectrics." Phys. Rev. 170, 401 
Oswald, R. 1977. Personal Communication. R. S. Landauer, Jr. and Company, Inc.

Sohrabi, M. 1974. "The Amplification of Recoil Particle Tracks in Fast Neutron Personnel Dosimetry." Health Phys. 27, 598-600

Sohrabi, M. November 1975. Unpublished Ph.D. Thesis. Georgia Institute of Technology

Sohrabi, M. and Morgan, K. Z. February 1976. "The Effect of Polycarbonate Foil Thickness on Electrochemical Etching Amplification of Recoil Partir.le Tracks for Fast Neutron Dosimetry " in the Proceedings of the Ninth Midyear Symposium of Health Physics Society, Denver, lolorado

Sohrabi, M. and Morgan, K. Z. May 1976. "Some New Characteristics of a Polycarbonate Fast Neutron Personnel Dosimeter" in the Proceedings of American Industrial Hygiene Conference; Atlanta, Georgia

Thorngate, J. H., Christian, D. J., and Littleton, C. P. 1976. "An Apparatus for Electrochemical Etching of Recoil Particle Tracks in Plastic Foils." Nucl. Inst. Methods 138, 561-563

Tommasino, L. and Armellini, C. 1970. "New Etching Technique for Damaged Track Detectors. Rad. Effects 20, 253-255

Young, D. A. 1958. "Etching of Radiation Damage in Lithium Fluoride." Nature. 182, 375 
ORNL/TM-6167

Dist. Category UC-41

Internal Distribution

$\begin{aligned} \text { 1. } & \text { J. A. Auxier } \\ 2 . & \text { D. J. Christian } \\ \text { 3-12. } & \text { S. J. Cotter } \\ \text { 13. } & \text { W. D. Cottrel1 } \\ \text { 14. } & \text { H. W. Dickson } \\ \text { 15-24. } & \text { R. B. Gammage } \\ 25 . & \text { W. R. Garrett } \\ 26 . & \text { L. W. Gilley } \\ 27 . & \text { F. F. Haywood } \\ 28 . & \text { G. S. Hil } \\ 29 . & \text { F. O. Hoffinan } \\ 30 . & \text { S. V. Kaye } \\ 31 . & \text { R. W. Leggett } \\ 32 . & \text { C. A. Little } \\ 33 . & \text { L. M. McDowe11-Boyer } \\ 34 . & \text { H. R. Meyer } \\ 35 . & \text { C. W. Miller } \\ 36 . & \text { R. E. Moore }\end{aligned}$

External Distribution

57. Nathaniel F. Barr, Division of Technology Overview, U.S. Department of Energy, Washington, DC 20545.

58. J. A. Broadway, Eastern Environmental Research Facility, P. 0. Box 61, Montgomery, Alabama 36101.

59. J. E. Christian, Bionucleonics Department, Purdue University, West Lafayette, Indiana 47907.

60. Roger J. Cloutier, Special Training Division, Oak Ridge Associated Universities, Oak Ridge, Tennessee 37830.

61. Enrico Conti, Radiological Assessments Branch, United States Nuclear Regulatory Commission, Washington, DC 20555.

62. T. V. Crawford, Savannah River Laboratory, Aikerl, Suuth Carolina 29801.

63. Keith F. Eckerman, Radiological Assessments Board, United States Nuclear Regulatory Commission, Washington, DC 20555.

64. G. G. Eichholz, School of Nuclear Engineering, Georgia Institute of Technology, Atlanta, Georgia 30332.

65. R. F. Johnson, Jr., University of Texas Medical Branch, Nuclear Medicine, Radiology Department, Galveston, Texas 77550.

66. R. R. Landolt, Bionucleonics Department, Purdue University, West Lafayette, Indiana 47907.

67. J. R. Maher, Division of Technology Overview, U.S. Department of Energy, Washington, DC 20545.

68. W. A. Mills, Criteria and Standards Division, United States Environmenta 1 Protection Agency, 401 M Street, SW, Washington, DC 20460.

69. John H. Thorngate, Hazards Control Division, Lawrence Livermore Laboratory, Livermore, CA 94550.

70. R. J. Vetter, Bionucleonics Department, Purdue University, West Lafayette, Indiana 47907.

71. P. L. Ziemer, Bionucleonics Department, Purdue University, West Lafayette, Indiana 47907. 
72. Research and Technical Support Division, DOE, ORO. 73-323. For distribution as shown in TID-4500 under category UC-41. 